IAB-DISCUSSION PAPER

$37 \mid 2020$ The role of unemployment and job change when estimating the returns to migration 


\section{The role of unemployment and job change when estimating the returns to migration}

Julian Emmler (Humboldt University Berlin),

Bernd Fitzenberger (IAB, Friedrich-Alexander University Erlangen-Nürnberg, IFS, CESifo, IZA, ROA)

Mit der Reihe „IAB-Discussion Paper“ will das Forschungsinstitut der Bundesagentur für Arbeit den Dialog mit der externen Wissenschaft intensivieren. Durch die rasche Verbreitung von Forschungsergebnissen über das Internet soll noch vor Drucklegung Kritik angeregt und Qualität gesichert werden.

The "IAB-Discussion Paper" is published by the research institute of the German Federal Employment Agency in order to intensify the dialogue with the scientific community. The prompt publi-cation of the latest research results via the internet intends to stimulate criticism and to ensure research quality at an early stage before printing. 


\section{Contents}

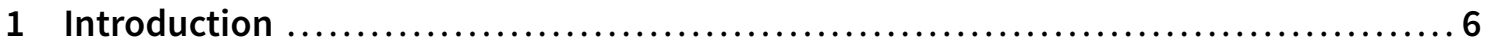

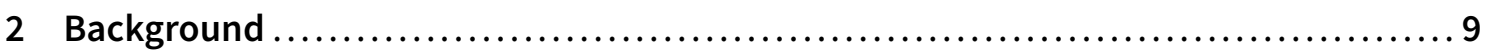

3 Labor Market Dynamics and Migration Costs ............................ 11

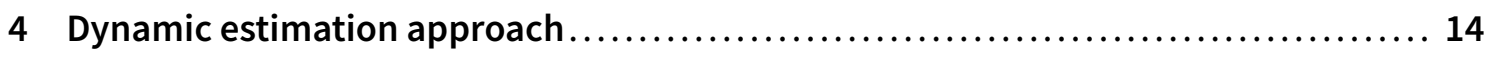

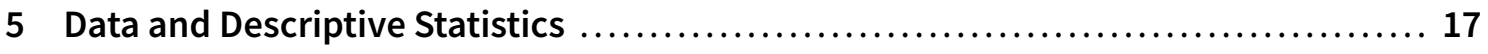

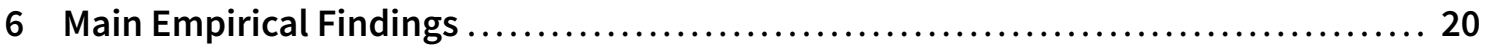

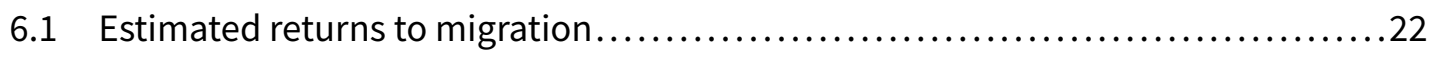

6.2 Returns by Prior Employment Status ................................... 24

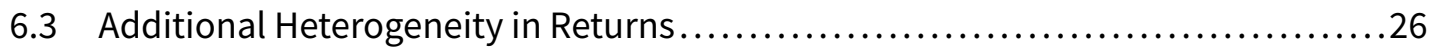

7 Robustness Checks.................................................. 28

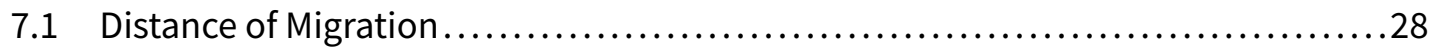

7.2 Regional Price Differences ...........................................29

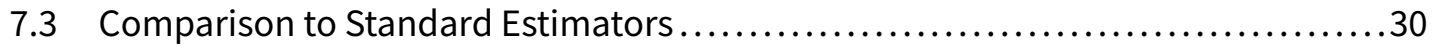

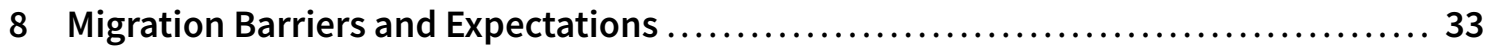

8.1 Financial and Psychological Costs ..................................... 35

8.2 Risk Aversion and Attitudes towards Migration ............................ 35

8.3 Expectations and Worries............................................ 36

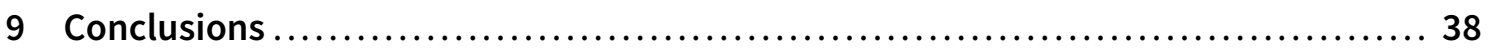

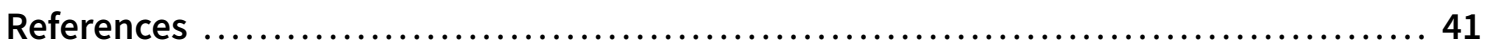

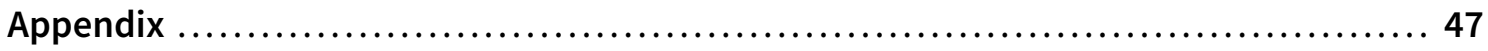

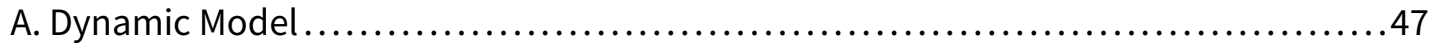

B. Temporal Alignment and Inverse Probability Reweighting ......................55

C. Tables .............................................................. 57

D. Figures ............................................................ 64 


\section{List of Figures}

Figure 1: Aggregate nominal Earnings and Unemployment in East Germany . ............10

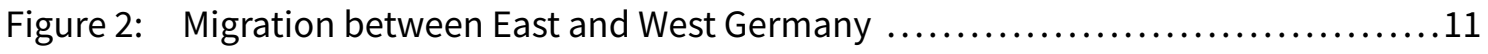

Figure 3: Earnings and Unemployment without IPW .............................. 21

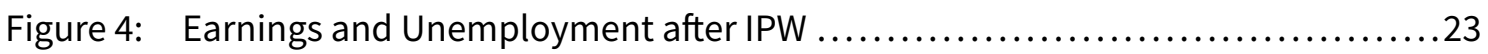

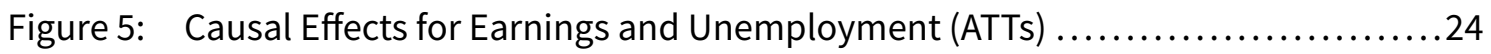

Figure 6: Outcomes by Prior Employment Status after IPW ....................... 26

Figure 7: Heterogeneity in ATT based on Gender .................................. 27

Figure 8: Heterogeneity in ATT based on Earnings in East Germany $\ldots \ldots \ldots \ldots \ldots \ldots \ldots \ldots 28$

Figure 9: Causal Effects for Earnings with and without short-distance Migrants (ATTs) ....29

Figure 10: Causal Effects for Earnings with and without RPI (ATTs) ..................... 31

Figure 11: Estimated Causal Effects for Earnings using Difference-in-Differences or using Yearly Data .................................................. 33

Figure 12: Monthly Earnings in the SOEP without (left) and with (right) IPW..............35

Figure 13: Model Visualization .......................................... 48

Figure 14: Migration Cohort 1994 - Pre-migration Temporal Alignment ................. 53

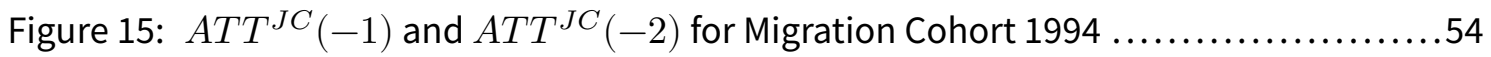

Figure 16: Earnings and Unemployment after IPW by treatment year .................64

\section{List of Tables}

Table 1: Descriptive Statistics ............................................. 19

Table 2: Moving Costs................................................... 36

Table 3: Behavioral Variables ................................................... 37

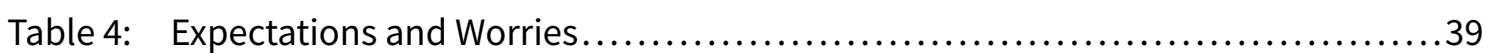

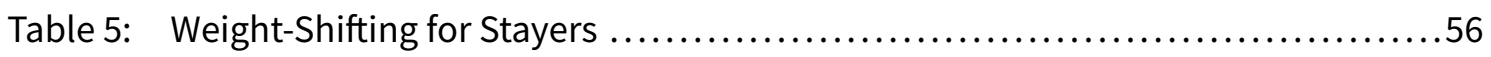

Table 6: Logit Models of Migration Determinants ................................. 58

Table 7: Means of Control Variables before and after IPW (BASiD) ...................... 59

Table 8: Means of Moving Costs and Behavioral Variables before and after IPW - SOEP ...60

Table 9: Means of Expectations and Worries before and after IPW - SOEP ..............61

Table 10: Attachment to Place of Living and Willingness to Move Years -4 to $-2 \ldots \ldots \ldots \ldots 62$

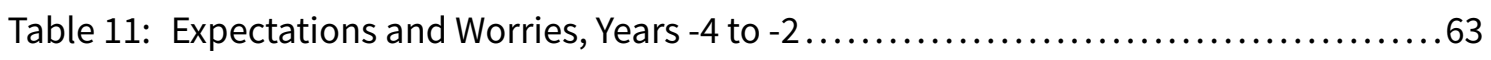




\section{Abstract}

Estimating the returns to migration from East to West Germany, we focus on pre-migration employment dynamics, earnings uncertainty, and job change. Migrants are found to be negatively selected with respect to labor market outcomes, with a large drop in earnings and employment during the last few months before migration. We find sizeable positive earnings and employment gains of migration both in comparison to staying or job change. The gains vary considerably with pre-migration earnings and with the counterfactual considered. Future migrants have worse expectations for their labor market prospects in the East and migrants show a greater openness to mobility.

\section{Zusammenfassung}

Unsere Schätzung der Erträge der Migration von Ost- nach Westdeutschland berücksichtigt die Beschäftigungsdynamik vor Migration, die Unsicherheit der Verdienste und den Arbeitsplatzwechsel. Migranten sind im Hinblick auf ihre Erwerbshistorie negativ selektiert, was sich insbesondere in einem starken Abfall der Verdienste und der Beschäftigung während der letzten Monate vor Migration zeigt. Unsere Analyse zeigt hohe positive Effekte der Migration auf Verdienste und Beschäftigung sowohl im Vergleich zu einem Verbleib als auch zu einem Arbeitsplatzwechsel in Ostdeutschland. Die Erträge hängen stark von den Verdiensten vor Migration und von der Vergleichssituation ab. Zukünftige Migranten erwarten schlechtere Arbeitsmarktchancen in Ostdeutschland und sie zeigen sich offener für Mobilität.

\section{JEL}

J61, R23, O15, P25

\section{Keywords}

migration, returns, selection, unemployment, moving costs

\section{Acknowledgments}

We thank Vojtech Bartos, Alexandra Spitz-Oener, Christian Dustmann, Josef Zweimüller, Hannah Liepmann, as well as audiences in the CRC/TRR 190 workshops and numerous seminars for helpful comments. We acknowledge financial support by the Deutsche Forschungsgemeinschaft (DFG) through CRC/TRR 190 "Rationality and Competition", Project A07 "Obstacles to convergence in regional development: Behavioral explanations". 


\section{Introduction}

Economic returns to migration and the costs of migration are key drivers of individual migration decisions. While a large part of the literature analyzes how the returns to skill and the uncertainty about labor market outcomes in the destination region affect migration (see Borjas (1987) - or among many others Parey et al. (2017) as a recent study), this paper estimates the causal returns to migration on labor market outcomes while focusing on pre-migration employment dynamics, earnings uncertainty, and job change in the source region. The empirical analysis considers the second wave of migration from East to West Germany a few years after the immediate surge in migration following German reunification. This is a case with a fairly low level of migration despite seemingly high migration returns and low apparent migration costs. ${ }^{1}$ Hence, our analysis also sheds light on the drivers and barriers to migration in such a setting.

As our key contribution, we estimate the average causal effects of migration for migrants both on employment and earnings, while accounting for a strong dip in employment and earnings during the last months before migration. Our findings imply that average returns to migration are positive for all groups, but the size of the returns crucially depends upon whether one considers remaining in the source region without starting a new job (simply denoted as staying) or starting a new job in the source region (simply denoted as job change) as counterfactual. Additionally, the returns to migration strongly depend upon the employment status and the earnings right before migration. Considering obstacles to migration despite positive returns, migrants differ substantially before migration from non-migrants with respect to non-monetary moving costs, namely regarding expectations about their economic future and their attitudes towards mobility.

For several reasons, migration from East to West Germany in the mid and late 1990s is an ideal setting for our empirical analysis. First, due to the long separation, the East and West German economies differed strongly with much better labor market chances in West Germany (Burda/Hunt (2001), Hunt (2006)). At the same time, differences in institutions, language or culture, which could be obstacles to migration, are largely absent. Second, East Germany underwent a substantial economic transition from a state-led economy towards a market

1 Annual migration peaked at almost 400 thousand individuals in 1989 and 1990 (Burda/Hunt, 2001). However, gross migration quickly fell below 200 thousand from 1992 onward until 1999, and net migration was close to zero in the mid and late 1990s, despite a substantial remaining gap in labor market chances between West and East Germany and despite the absence of legal restrictions or language/cultural differences (Hunt (2006), FuchsSchündeln/Krueger/Sommer (2010)). 
economy, causing long-lasting economic instability. In contrast, the West German economy represented a stable and high-wage labor market, allowing us to focus our analysis on the influence of labor market developments in the source region. Third, the unexpected and profound changes caused by reunification introduce a randomness into individual labor market histories helping us to identify the causal returns to migration. Becoming unemployed was likely to be less selective in East Germany than in developed Western countries at the time. Based on novel administrative panel data (BASiD data) which include labor market outcomes before and after migration, we focus on the second wave of migrants from East Germany after reunification, who were not leaving immediately during 1989 or 1990 but migrated later in response to deteriorating labor market conditions.

As theoretical background regarding the determinants of migration decisions and the selection of migrants, a large literature relies on an augmented Roy model, as popularized by Borjas (1987). ${ }^{2}$ The basic Roy model predicts positive (negative) selection of migrants, depending upon whether the returns to skill are higher (lower) in the destination region compared to the source region. However, the aggregate measures often used as proxies for skill returns do not necessarily reflect the individual migrant's returns. Moreover, the model does not include uncertainty about labor market outcomes in the source region and most studies applying the model ignore the role of unemployment for migration decisions. We analyze whether and to what extent these factors affect migration returns, thus being drivers of the migration decision. ${ }^{3}$

Our empirical analysis estimates the average effect of treatment (三 migration) on the treated (三 migrants) based on detailed administrative panel data (BASiD) at the monthly frequency. ${ }^{4}$ The data show a distinct pre-migration dip in earnings and employment a few months before migration, mostly driven by a substantial increase in the unemployment rate of prospective migrants. To capture this development, we carefully align migrants and our control group with respect to the timing of migration. To allow for different counterfactual labor market de-

2 Empirical tests of different variants of this model can be found in, among others, Borjas/Bronars/Trejo (1992), Hunt/Mueller (2004), Chiquiar/Hanson (2005), Kaestner/Malamud (2014), Parey et al. (2017), Bartolucci/ Villosio/Wagner (2018). Brücker/Trübswetter (2007) use the model as a framework to analyse the selection of East German migrants to West Germany.

3 Other recent studies which analyze the selection of migrants in the context of rural-to-urban migration are Young (2013), De la Roca/Puga (2017), or De la Roca (2017). These studies find a positive selection of migrants because skilled individuals can obtain higher returns to their skills in urban regions compared to rural regions. Lkhagvasuren (2014) and Amior (2015) analyze the selection of migrants between regions by skills. Arntz/Gregory/Lehmer (2014) relate differences in the aggregate unemployment rates between different German regions to the selection of internal migrants. The link between individual unemployment experience and migration is addressed by Herzog/Schlottmann (1984) and Pissarides/Wadsworth (1989), see also the literature survey in Herzog/Schlottmann (1993). The importance of economic conditions in the source region is discussed in Herzog/Schlottmann (1982). Finally, Huttunen/Moen/Salvanes (2018) and Fackler/Rippe (2017) consider the effect of mobility on earnings of displaced workers. The latter study uses the Socio-economic Panel to analyze interregional migration in Germany. Caliendo/Künn/Mahlstedt (2017) find positive effects of mobility assistance for the unemployed on future labor market outcomes in Germany.

4 Note that we estimate the returns to migration for migrants. Hence, the results are relevant for East German non-migrants who are similar to migrants with respect to the drivers of labor market outcomes, but who differ in terms of expectations and moving costs. 
velopments in East Germany, we define two different control groups. We thus estimate the effect of two different treatments. The first treatment involves migration-vs-staying, where stayers are individuals who stay in East Germany and who do not find a new job in the same year, i.e. who remain unemployed or stay in their job. The second treatment involves migrationvs-job-change, where job changers are individuals who find a new job in East Germany during the same year (similar to Ham/Li/Reagan (2011)). We find that migration-vs-job-change involves substantially and consistently lower causal returns to migration compared to migrationvs-staying.

Experimental settings allowing to identify the returns to migration are very rare (an exception being the migration lottery in Tonga used by McKenzie/Stillman/Gibson (2010)). Our rich data offer detailed information on individual, regional, and employer characteristics as well as on labor market history in East Germany before migration. Furthermore, East Germany experienced a strong negative labor demand shock, which limited the role of unobserved individual heterogeneity for selection effects regarding labor market outcomes. This justifies a selection-on-observables assumption similar to Ham/Li/Reagan (2011) or Zaiceva (2010). ${ }^{5}$

There is some disagreement in the international literature on the sign of the returns to migration, ${ }^{6}$ while the literature on East-to-West migration in Germany concludes that there are substantial positive returns to migration, often based on descriptive evidence and using data that do not allow to account for employment dynamics before migration. Burda/Hunt (2001) and Hunt (2006) provide descriptive evidence for positive wage returns to migration in the 1990s (see also Brücker/Trübswetter (2007) and Alm/Engel/Weyh (2014)). Furthermore, Hunt (2006) shows that job loss is a driver of migration. Heise/Porzio (2019) find that earnings of Eastborn migrants to West Germany increase compared to job changers within East Germany. They explain the low migration to West Germany by labor market frictions and a home bias of East Germans. Our analysis extends upon the existing evidence in the following important aspects: We provide causal estimates on the returns to migration while accounting for the dynamics before migration (especially regarding unemployment) and considering different counterfactuals in the source country, we use detailed panel data at a monthly frequency, and we analyze the heterogeneity of returns.

Our causal estimates of the returns to migration on earnings and employment prove positive and substantial, with the returns of migration-vs-job-change being much smaller than the returns of migration-vs-staying. We find returns to migration of 20 percent in daily earnings compared to job changers, with returns being quite stable over the course of two years after migration and across migration cohorts. Compared to stayers, the initial gains for migrants

5 Different non-experimental approaches have been used in the literature, such as Heckman (1979) type selection models to control for unobservables driving the selection of migrants and stayers (e.g. Nakosteen/ Zimmer (1980), Tunali (2000), Nakosteen/Westerlund (2004), Bartolucci/Villosio/Wagner (2018)), fixed-effects or difference-in-differences (e.g. Yankow (2003), Lehmer/Ludsteck (2011)) or instrumental variable estimation (Venhorst/Cörvers (2018), Zaiceva (2006), Ham/Li/Reagan (2011)).

6 Most studies finds positive returns, but there are studies with insignificant effects (for example Zaiceva (2006)) or even negative effects (Borjas/Bronars/Trejo (1992), Tunali (2000)). 
are substantially higher (106 percent higher earnings immediately after migration), and the gains decline somewhat over time amounting to 36 percent two years after migration. A persistently higher employment rate of those who change jobs compared to stayers is the key driver of the different returns to migration.

Our analysis reveals strong heterogeneity in the returns by gender and by labor market outcomes before migration. Returns are higher for males and for individuals with lower premigration earnings and less stable employment. Heterogeneity of returns may thus explain non-migration of those with stable labor market histories and high paying jobs. When controlling for regional price differences, returns to migration are lower but still remain substantial. At a methodological level, accounting for the dynamics of unemployment is crucial in light of the pre-migration dip in earnings and employment because more than 50 percent of the migrants are unemployed before migration. We show that a standard Difference-inDifferences approach or using data at the annual frequency yields downwardly biased estimates when taking our preferred estimates as benchmark.

In light of the low net migration between East and West Germany after 1992, we also investigate non-financial/behavioral barriers to migration. ${ }^{7}$ Because BASiD lacks information on these, we provide evidence based on the Socio-economic Panel (SOEP) for Germany. Conditional on the control variables used in the analysis of returns, migrants prove less risk-averse, less attached to their place of living, less likely to be married, and they have less children as well as a higher willingness to move. Additionally, prospective migrants (and job changers) worry more about their economic future compared to stayers. In summary, worries about one's own economic situation, the perceived need to find a new job and low barriers to migration are important drivers of migration. Additionally, being employed in a stable job in East Germany strongly reduces the willingness to migrate, most likely because returns to migration are much lower for such workers.

The remainder of paper is structured as follows: Section 2 reviews the historical background. Theoretical consideration for the role of source region characteristics are developed in Section 3, and Section 4 presents the dynamic treatment approach. Section 5 describes the administrative panel data used. The main empirical findings are discussed in Section 6, while Section 7 provides additional analyses. Section 8 turns to the analysis of migration costs. Section 9 concludes. The appendix provides further details.

7 In a recent study, Adda (2019) analyzes the sources of persistent economic differences between the North and the South of Italy. Even real income differences show some positive effect on interregional mobility, he finds that in real terms the two regions differ much less than in nominal terms. Furthermore, the quality of life plays a more important role for white collar workers and moving costs are high. All three effects explain the fairly low level of regional mobility from the South to the North. 


\section{Background}

Starting in 1990, steps for a swift political and economic integration of East Germany into the Federal Republic of Germany were implemented. In the early 1990s, many observers expected a convergence of wages in the medium run (Burda (1993)). East German real wages rose substantially in the first years after reunification, increasing by on average 83 percent from 1990 to 1996 according to Hunt (2000). However, this process of convergence stagnated after a while. The left graph in Figure 1 shows that average earnings in the East remained at around 75 percent relative to West Germany between the mid 1990s and the late 2000s and have increased to about 80 percent since. ${ }^{8}$ Many authors believe that the adjustment of wages in East Germany strongly contributed to the surge in unemployment in East Germany (examples include Burda/Hunt (2001) and Snower/Merkl (2006)). Between 1989 and 1992, the employment rate fell from 89 percent to 73 percent in East Germany (Hunt, 2000). ${ }^{9}$ The graph on the right in Figure 1 shows that the unemployment rate in East Germany was much higher than in West Germany and there was only a slow decline in recent years.

Figure 1: Aggregate nominal Earnings and Unemployment in East Germany
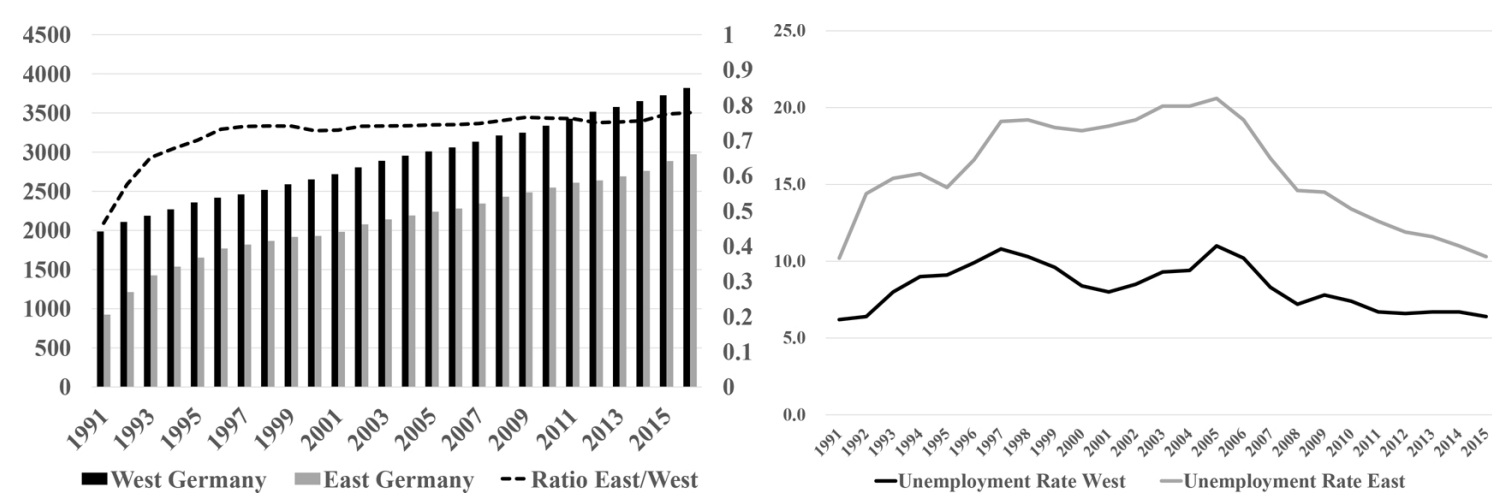

Notes: The figures show average earnings (left) and the rate of unemployment (right) in East and West Germany for different years. In the first figure, the left vertical axis represents nominal values in Euro and the right vertical axis represents the ratio of earnings. Data on earnings are taken from the German Statistical Office. Earnings are nominal average monthly pre-tax earnings from work in East and West Germany. Unemployment rates are taken from the "Bundesagentur für Arbeit" and are based on all registered unemployed and all workers who are not self-employed or employed by the military.

Source: Own calculations based on the German Statistical Office and the Federal Employment Agency.

In the light of the documented persistent East-West differences in labor market outcomes, migration to the West appears attractive. However, Figure 2 shows a different picture for gross East-to-West and West-to-East migration as well as for net migration from 1989 to 2013. Net migration to the West was high in the early years after reunification in 1989 to 1991 and then declined swiftly until it picked up again in the late 1990s. In recent years, net migration from

8 Our findings show that a sizeable earnings gap exists in both nominal and real terms (here real terms means adjusted for differences in the regional price index).

9 Liepmann (2018) shows that the deteriorating labor market conditions in East Germany had strong behavioral effects, with the study focusing on the decline of fertility. 
East Germany converged to zero. ${ }^{10}$ Even though migration was still sizeable after the first strong migration wave of the early 1990s, the persistence of economic differences and the relative ease of migration with regard to cultural differences or bureaucratic hurdles could have been expected to create an even greater number of migrants who wanted to improve their living standards by taking up work in West Germany.

Figure 2: Migration between East and West Germany

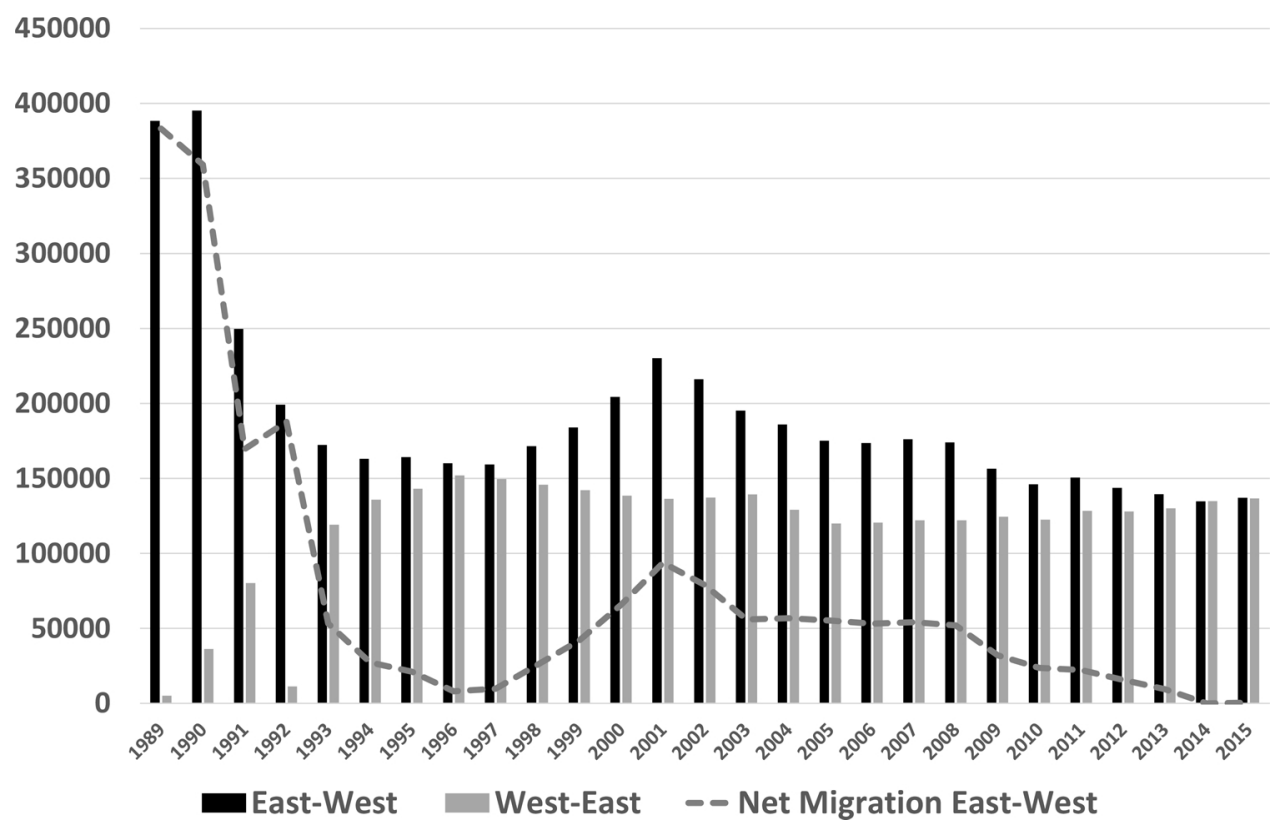

Notes: The figure shows the number of people moving from East German regions to West German regions and vice versa. The dashed line shows net migration flows from East German regions to West German regions. Migration figures are taken from the German Statistical Office. Migrants are individuals who changed their registered place of living from East to West Germany or vice versa (thus no commuters or individuals who register a secondary residence are included). Berlin is divided between East and West.

Source: Own calculations based on the German Statistical Office.

\footnotetext{
10 This does not imply that in the mid and late 1990s as many West Germans - i.e. individuals living in West Germany in 1989 - migrated to East Germany as East Germans - i.e. individuals living in East Germany in 1989 - migrated to West Germany, because a substantial share of West-to-East migrants were East Germans who returned from West Germany. Thus, one should not interpret the development of net migration as East Germany becoming more attractive for West Germans to migrate to, but rather reflecting sizeable return migration of East Germans. Additionally, these figures only count East Germans who move to West Germany, thus excluding the large number of East-to-West commuters.
} 


\section{Labor Market Dynamics and Migration Costs}

The most popular theoretical model to explain the selection of migrants (and thus the migration decision) is the augmented Roy model described by Borjas (1987). The focus of this model lies on the returns to skill in the destination and the source region, as well as on earnings uncertainty in the destination region and (e.g. Chiquiar/Hanson (2005)). However, the model does not account for the labor market dynamics in the source region before and after migration (especially transitions between employment and unemployment) and the implications for earnings uncertainty. Furthermore, (non-monetary) moving costs typically play only a small role in most studies based on the model. Both aspects are particularly important in settings in which individuals contemplate migration from an economically worse and unstable source region (e.g. facing a high risk of becoming/staying unemployed) to an economically more stable destination region. ${ }^{11}$ This point is particularly important in our case with migrants having excellent information about labor market chances in the destination region and facing low moving costs. The situation in the source region then explains the negative selection of migrants that we find in our data. ${ }^{12}$

As conceptional focus of our analysis, we stress four key aspects. First, we scrutinize the labor market dynamics (earnings and employment) of migrants before migration. We show that changes in pre-migration earnings and employment outcomes act as key drivers of migration. Therefore, a dynamic treatment approach (as described in section 4) has to account for the timing of migration with regard to changes in individual labor market outcomes (e.g. losing one's job) in the source region, which requires the availability of high-frequency panel data.

The second aspect concerns expectations about future labor market chances, which can have

11 Kennan/Walker (2011) consider the optimal sequence of location decisions focusing on the expected income in the destination region. The authors stress the dynamic nature of the migration decision which is also central to our empirical analysis. Similar to our approach described below (and formally developed in Appendix 9) migration increases when there is a negative income shock in the current location. A polar case is discussed by Armstrong/Lewis (2012) for the case with high financial moving costs and capital constraints. In this setting, individuals with higher wages in the source region can afford the moving costs earlier thus implying a positive selection of migrants.

12 The negative selection of migrants with regards to earnings, wages and employment chances in East Germany is not easily explained by analyzing differences in wage returns to individual characteristics on the basis of the augmented Roy model used by most of the literature. Empirical studies mostly find that wage dispersion (Burda/Hunt (2001) and Fuchs-Schündeln/Krueger/Sommer (2010)) and returns to observable skills (for example to age/experience (Krueger/Pischke (1995), Jurajda/Harmgart (2007), Orlowski/Riphahn (2009)) and to education (Krueger/Pischke (1995))) are higher in West Germany, especially in the early and mid-1990s. Therefore, the standard Roy model would predict that East-to-West migrants are either positively selected on wages and observables (Parey et al. (2017)) - or not selected at all. This line of argument ignores that unemployment can act as a strong push factor for migration and that workers who lose their job are typically less skilled than the average worker. Other existing theoretical models used in the literature to analyze East-to-West migration do not focus on the selection of migrants, returns to migration, or the role of unemployment (see e.g. Heise/Porzio (2019), Burda (1995)). 
a strong impact on migration decisions. Hence, in a situation of high labor market uncertainty, unemployed individuals or individuals with low earnings may migrate because they do not expect their situation in the source region to improve quickly. Specifically, if employment chances are expected to deteriorate strongly after a job loss, then the probability to migrate increases. ${ }^{13}$ This holds in particular, when individuals are overpessimistic about their future labor market prospects in the source region.

Third, we distinguish explicitly between job change and staying as alternative counterfactuals to migration. In response to deteriorating employment chances in the source region, individuals may change to a different job in the source region instead of migrating. Ham/Li/Reagan (2011) consider job change as the relevant counterfactual because migration also involves a job change. We think however, that both counterfactuals are of interest in a setting with strong mobility between employment and unemployment and we estimate the treatment effect with respect to both counterfactuals.

Finally, we investigate perceived (non-monetary) migration costs based on pre-migration survey information. In addition to the proxies for migration costs often discussed in the literature (for example marital status, children), we also consider other potential behavioral determinants like attitudes towards migration or risk aversion.

Appendix 9 develops a formal dynamic model of the migration decision that captures the most important aspects of interest for our analysis. Here, we sketch the model in a nutshell. We posit a three period model. In period 0 , it is given whether an individual is employed or not. Employment in the source region in periods 1 and 2 follows a Markov process, with the probability to remain employed being strictly higher than the probability to become employed. Individuals can migrate at the beginning of periods 1 and 2. Further key assumptions are that wages in the destination and the source region are assumed to be constant and that there are sizeable migration costs. Restricting uncertainty to job loss and job finding in the source region greatly simplifies the analysis while focusing upon the main risk faced by East Germans during the transition period in the 1990s. The decision to migrate is a function of the employment state and expectations regarding state dependent employment probabilities in the source region.

The key model implications are the following: The migration probability falls with the wage in the source region and with migration costs, it is higher for unemployed than for employees, and it rises with the wage in the destination region. Since expectations about future employment matter, the migration probability falls with better employment prospects in the source region. Therefore, key obstacles to migration are high migration costs and overly optimistic

13 For simplicity, our model assumes that the wage in the West is unaffected by individual employment shocks in the East. This assumption seems justified because the risk of job loss in East Germany is high due to the reunification-caused transition process, implying that a job loss in East Germany is not viewed as a negative signal by West German employers. Furthermore, the qualitative results of the model still hold as long as labor market prospects in West Germany are less negatively affected by job loss than labor market prospects in East Germany. 
expectations about labor market chances in the source region. Among individuals, who migrate at the beginning of period 2, the employment situation or the expectation about the future employment prospects must have deteriorated in period 1 relative to period 0 or migration costs must have fallen over time. The model implies a negative selection of migrants with respect to labor market outcomes in the source region and it is consistent with the dynamic treatment approach in section 4.

\section{Dynamic estimation approach}

Our goal is to estimate the causal effect of East-to-West migration on earnings and unemployment, focusing on the average effect of treatment (三 migration) for the treated (三 migrants) [ATT]. The observed outcome (earnings, unemployment) is $Y=D \cdot Y_{1}+(1-D) \cdot Y_{0}$, where $Y_{1}$ and $Y_{0}$ are the potential outcomes under migration or non-migration, respectively, and $D$ is the migration dummy. We consider two counterfactual outcomes $Y_{0}$ corresponding to two different treatments. These counterfactuals are (i) staying in the East without starting a new job in in a given year, corresponding to the treatment migration-vs-staying, and (ii) starting a new job in the same month as migration (including finding a job after unemployment), corresponding to the treatment migration-vs-job-change. The non-migration outcome entails the possibility of future migration.

Identification relies on a Conditional Independence Assumption (CIA), similar to Ham/Li/Reagan (2011) or Zaiceva (2010). Our rich panel data enable us to control for individual employment histories on a monthly basis, socio-demographic characteristics, employer information, and detailed regional information, which arguably allow us to predict well the counterfactual outcomes for both treatments. In particular, we condition on labor market histories up to the month before migration, which accounts for unobservable factors affecting labor market success. Based on the available data, it would be difficult to justify an instrumental variable or selection approach. ${ }^{14}$ Our CIA - to be spelled out below - implies that given our rich conditioning set, selection into migration is not driven by factors related to future labor market outcomes in the East (recall that we restrict estimation to the ATT). This does not preclude selection on unobservables relevant for West German labor market outcomes, but which are

14 A sizeable number of studies use a standard cross-sectional Heckman (1979) two step estimator, see e.g. Tunali (2000), Brücker/Trübswetter (2007), or Bartolucci/Villosio/Wagner (2018). In addition to relying on strong distributional assumptions, this requires a credible exclusion restriction (essentially an instrument), being difficult to justify based on administrative data from 1992 onward (see section 5). For our setting, we have to account for dynamic selection, because people migrate in different time periods and migrants were non-migrants before. Such a setting would even require time-varying instruments (see Heckman/Navarro (2007)). 
not drivers of labor market success in East Germany. ${ }^{15}$ The sudden transition process in East Germany made labor market success in East Germany more random. Arguably this reduced the importance of unobserved determinants of wages and job loss in East Germany (for example through the devaluation of individual human capital in the aftermath of reunification - see e.g. Orlowski/Riphahn (2009) and Smolny/Kirbach (2011)) for evidence on this devaluation) which further helps identification. Focussing on the ATT means that our results apply to the large group of East Germans who are similar in observable and unobservable skills to migrants. Estimation of the average treatment effect in a dynamic setting would require much stronger identifying assumptions. By conditioning on individual employment histories based on monthly data, we extend upon a standard difference-in-differences (DiD) estimator. The latter is not justified because we observe a disproportionate pre-migration dip in earnings and employment during the last months before migration takes place, similar to the widely documented Ashenfelter's dip studied in the training literature (Heckman/Smith, 1999).

Most of the literature estimating the ATT of migration uses non-migrants in the source region as control group. As noted by Ham/Li/Reagan (2011) for the US, migration of a worker typically entails a job change, thus suggesting to focus on the migration-vs-job-change treatment to isolate the returns to job changing from returns to migration. We view staying in the East without starting a new job and job change in the East as two alternative treatments in a multiple treatment setting, representing two possible counterfactual treatments while remaining in the East, and we estimate the causal effect of migration against both (Imbens (2000), Lechner (2001)). For migration-vs-job-change, we follow Ham/Li/Reagan (2011) in using job changers who do not migrate to the West as the control group. For migration-vs-staying, our control group involves those East Germans who do not migrate and who either keep their job in the East or who lose their job (or remain unemployed) without starting a new one in a given year. We assume that the CIA holds for both treatments. However, if one is concerned that we may not be able to control sufficiently for the selection into staying versus job change in the East, one should view the two counterfactuals as alternative estimates of the expected nonmigration outcome in the East, thus providing a robustness check motivated by the concerns raised in Ham/Li/Reagan (2011).

We model the selection into migration as a dynamic process. Individuals who decide not to migrate in time period $t$ can still do so later when circumstances have changed. Including only never-migrants in the control group would condition on future outcomes. We follow Sianesi (2004) and Biewen et al. (2014) in estimating the effect of treatment (三 migrating now) versus waiting. This means that we include future migrants (and future job changers) in the control group for period $t$. Our analysis uses data at the monthly frequency and $t$ is the calendar month of migration.

15 This is a version of the two-skill setting in Dustmann/Glitz (2011). As long as migration is not selective in unobserved skill valued in East Germany, the possibility that migration is selective in unobserved skills valued only in West Germany does not invalidate our ATT estimates. We argue that our detailed set of controls accounts sufficiently for the skills valued in East Germany. 
Formally, the ATT for the treatment migration-in- $t$-versus-waiting on outcomes in $t+a$ is given by

$\operatorname{ATT}_{t}(a)=E\left(Y_{1, t}(t+a)-Y_{0, t}(t+a) \mid D_{t}=1, D_{1}=\ldots=D_{t-1}=0\right)$,

where $D_{t}$ denotes the dummy for migration in period $t, Y_{1, t}(t+a)$ the migration outcome, and $Y_{0, t}(t+a)$ the non-migration outcome in period $t+a$, where $a$ measures months before/after treatment. Both outcomes are associated with the treatment sequence no-migration-up-to$t$, i.e. $D_{1}=\ldots=D_{t-1}=0$. We view migration as an absorbing state, meaning $D_{t}=$ 1 implies that the individual is not at risk of migrating to the West after period $t$ and thus not to be included in the control group for future migrants. This means that we estimate the return to the first migration only, while including post-migration outcomes even after return migration.

The identification of $A T T_{t}(a)$ builds on a dynamic version of the CIA such that conditional on the covariates and the labor market history up until period $t-1$ the potential non-treatment outcome $Y_{0, t}(t+a)$ from $t$ onward $(a \geq 0)$ is conditionally mean independent of migration in period $t$. Formally, the dynamic CIA we assume is

$E\left(Y_{0, t}(t+a) \mid D_{t}=1, D_{1}=\ldots=D_{t-1}=0, X_{t}\right)=E\left(Y_{0, t}(t+a) \mid D_{t}=0, D_{1}=\ldots=D_{t-1}=0, X_{t}\right)$,

where $X_{t}$ involves all - possibly time-varying - covariates and lagged labor market outcomes.

As we document for our data below, migrants experience a substantial decline in employment and earnings before migration, which is clearly visible based on monthly data. Because of this pre-migration dip, it is important to align migrants and comparable non-migrants by their outcome history until period $t-1$, the month before treatment time. Simply comparing migrants and non-migrants at a specific point in time would neglect difference in shortrun pre-migration outcome dynamics. Similarly, a Difference-in-Differences estimator would only account for permanent outcome differences.

For the estimation of $A T T_{t}(a)$, we first align the treated and the non-treated by treatment month $t$ and we then control for differences in covariates and outcome history. For the control group of job changers, migrants are compared to those changing jobs in the same month when migration takes place. For stayers, the temporal alignment is less obvious because every month could be the counterfactual "month of migration". As control group, we use all stayers as observed in the year of migration of a specific migration cohort. Non-migrating unemployed are treated as job changers if they start a job during the calendar year of migration. The remaining unemployed who do not start a job during this year are treated as stayers. The appendix includes further details on the alignment. For each treatment month $t$, we estimate the ATTs for months 0 to 24 after treatment in $t$ as well as the pre-treatment differences for the 24 months before $t$, i.e. the $A T T_{t}(a)$ 's are estimated based on observed outcomes in $t+a$, where $a=-24, \ldots, 24$. The migration cohort ( $c$ : year of migration) specific $\operatorname{ATT}^{c}(a)$ 
is estimated as a weighted average of $A T T_{t}^{c}(a)$ [ $\equiv A T T_{m}^{c}(a)$ with $t$ representing month $m$ (=Jan,Feb,...) in year $c$ ] using the monthly share of migrants as weights (see Appendix for details). Finally, the overall effect $A T T(a)$ is estimated as the weighted average $A T T^{c}(a)$ over all sample years.

To account for the differences in observables $X_{t}$ (covariates, outcome history up to $t-1$ ) between treated and non-treated after temporal alignment, we use inverse probability reweighting (IPW) based on normalized weights (Busso/DiNardo/McCrary (2014)). IPW equalizes the distribution of observables between treated and non-treated. We first estimate the probability of migration in month $t$ (the propensity score) using a logistic regression of the migration dummy on $X_{t}$. Since the determinants of migration might change over time, the propensity score is estimated based on an (unbalanced) panel logit regression separately for every year, also accounting for month fixed effects. Then, we reweight the distribution of observables in the control groups towards the treatment group. Note that the group of migrants is much smaller than our two control groups and the necessary overlap of support for the distribution of the propensity score for the ATT is given. ${ }^{16}$ For the two treatment cases, we estimate separate logit models based on migrants and the specific control group only. The reweighted outcomes before migration $(a<0)$ allow for an assessment of how well the reweighting strategy works in balancing the outcome history. The outcomes for the 24 months after migration provide estimates of the treatment effects. To account for the possibility of remaining covariate imbalance and to explore the heterogeneity of treatment effects, we also estimate ex post outcome regressions after inverse probability weighting as in Fitzenberger/Sommerfeld/Steffes (2013). Inference is based on bootstrapped asymptotic standard errors, clustered at the individual level.

\section{Data and Descriptive Statistics}

The core data used stem from the "Biographies of selected insurance agencies in Germany" (BASiD), a high-quality administrative panel data set linking a 1 percent sample of the German pension insurance accounts with the entries of the same individuals in the "Integrated Employment Biographies" (IEB) (Hochfellner/Müller/Wurdack (2012)). The BASiD covers all individuals with at least one employment record with social security contributions, comprising about 80 percent of the German workforce (excluding civil servants, self-employed, marginally employed). Provided the employment criterion is satisfied, the data also include information on registered unemployment, additional schooling, or maternity leave. Attractive features of

16 Note that we can not estimate the average treatment effect of migration for the non-migrants (further details on the overlap of the propensity score distributions are available upon request). 
the BASiD are that employment before reunification is recorded and that the sample size is much larger compared to the SOEP, the data source used most often in the literature on Eastto-West migration.

Complete labor market histories in the East after reunification are recorded in BASiD from 1992 to 2006, allowing us to consider migration from 1994 to 2004 while controlling for two years of history and estimating post-migration effects for two years. Migrants in this second wave of migration differ from the large number of migrants in the first wave of migration in 1989 and 1990. On the one hand, individuals with low migration costs are likely to have migrated in the first wave in light of the strong economic incentives for migration. On the other hand, the majority of migrants in the second wave has experienced some unemployment in East Germany after reunification, as a consequence of the restructuring of the East German economy.

Our analysis is restricted to individuals who worked in East Germany before reunification. ${ }^{17}$ Migration is defined as a change in the location of the workplace from East to West, which includes commuting. We focus on the first migration spell only, thus abstracting from return migration and repeated migration. Note that the vast majority of migrants migrates only once to West Germany. We only consider a migration episode if it lasts at least three months. To include individuals who are likely to be in the labor market for most of our period of analysis, we only consider individuals born after 1939 and who are thus at most 50 years old in 1990 at the time of reunification.

Table 1 shows basic descriptive statistics for the time period 1994 to 2004, as measured one month before migration or job change - except for stayers, for whom all observations are used. Compared to stayers, migrants and job changers are more likely to be male. Migrants are also younger than job changers and stayers, the latter two being close in age. We find no selection regarding education, except for a slightly higher (lower) share of university graduates (apprenticeship degree holders) among stayers. A higher share of migrants and job changers work in construction prior to migration. In particular, this holds for migrants in the early 1990 s before the construction boom in the East. In contrast, there are very few migrants who were former public employees, while their share is much higher among job changers.

With regard to labor market history, unemployment during the past 12 months, unemployment since reunification, and job changes in the past are more common among migrants and job changers compared to stayers. In our analysis, unemployment includes all times when an individual is not in (social-security registered) work or training. In terms of spatial allocation, the distributions of the last job across federal states are very much alike for job changers and

17 These individuals experienced reunification as a sudden shock in their labor market environment, and they had to decide whether to migrate or not. Their motives are likely to differ from those who did not already work in GDR times, and they form the much larger group in the 1990s. Furthermore, it is difficult to identify those East Germans who never worked in East Germany before reunification, because individuals are first recorded when they start their first job. Since there is evidence for young East Germans sorting into studying or taking up an apprenticeship in West Germany, including individuals without employment in the East during GDR times might introduce a sorting bias. 
Table 1: Descriptive Statistics

\begin{tabular}{|c|c|c|c|}
\hline \multirow[b]{2}{*}{ Variable } & \multicolumn{3}{|c|}{ Groups } \\
\hline & Migrants & Stayer & Job Changer \\
\hline Female & $36 \%$ & $55 \%$ & $50 \%$ \\
\hline Age & 39.33 & 42.11 & 40.81 \\
\hline \multicolumn{4}{|l|}{ Education } \\
\hline High School & $3 \%$ & $4 \%$ & $3 \%$ \\
\hline Apprenticeship & $85 \%$ & $82 \%$ & $85 \%$ \\
\hline University & $12 \%$ & $15 \%$ & $12 \%$ \\
\hline \multicolumn{4}{|l|}{ Industry in Last Job } \\
\hline Agriculture, Energy and Mining & $4 \%$ & $4 \%$ & $5 \%$ \\
\hline Manufacturing & $15 \%$ & $16 \%$ & $13 \%$ \\
\hline Construction & $22 \%$ & $12 \%$ & $17 \%$ \\
\hline Trade, Transport and Communication & $13 \%$ & $12 \%$ & $12 \%$ \\
\hline Services & $30 \%$ & $34 \%$ & $32 \%$ \\
\hline Banking and Insurance & $10 \%$ & $7 \%$ & $10 \%$ \\
\hline Non-commercial Enterprises, Civil Servants & $6 \%$ & $14 \%$ & $12 \%$ \\
\hline \multicolumn{4}{|l|}{ Federal State of Last Job } \\
\hline Berlin & $3 \%$ & $6 \%$ & $7 \%$ \\
\hline Brandenburg & $18 \%$ & $15 \%$ & $15 \%$ \\
\hline Mecklenburg-Vorpommern & $13 \%$ & $12 \%$ & $12 \%$ \\
\hline Saxony & $28 \%$ & $34 \%$ & $31 \%$ \\
\hline Saxony-Anhalt & $21 \%$ & $19 \%$ & $20 \%$ \\
\hline Thuringia & $17 \%$ & $14 \%$ & $14 \%$ \\
\hline Share Unemployed & $1223 \%$ & $1236 \%$ & $1239 \%$ \\
\hline \multicolumn{4}{|l|}{ Number of Months } \\
\hline in Unemployment in last 12 Months & 7.48 & 3.95 & 6.41 \\
\hline Number of Job Changes since 1992 & 20.77 & 14.34 & 21.16 \\
\hline \multicolumn{4}{|l|}{ Share of months in unemployment } \\
\hline since reunification & $30 \%$ & $53 \%$ & $33 \%$ \\
\hline Median Earnings in Firm & 55.13 & 60.24 & 54.65 \\
\hline Observations & 2598 & 306116 & 51730 \\
\hline
\end{tabular}

Notes: Data for Migrants and Job Changers are from 1 month before migration/job change, for stayers, observations for all time periods are used. Observations are weighted by population weights. Civil servants only encompass a subset of all civil servants, since many civil servants in Germany have a special status ("Beamte") exempting them from social security contributions. Thus, they are not included in our data. Some covariates are suppressed for the sake of readability. The full list of covariates and their means for the three groups can be found in Table 7 .

Source: Own calculations based on BASiD 5109. 
stayers. Relative to the two other groups, migrants more often come from Thuringia and Brandenburg and less often from Saxony. The share of migrants from Berlin is low because moving from East Berlin to West Berlin is excluded since it just involves changing workplace within the same city. Migration from other locations in East Germany to West Berlin is counted as migration, but the results are robust if these migration spells are also excluded. Overall there are substantial differences between migrants and stayers in observable characteristics, with job changers being more similar to migrants (see also Ham/Li/Reagan (2011)).

Our IPW approach makes use of the rich set of socio-demographic covariates available in BASiD to align treated and non-treated based on the values one month before migration. ${ }^{18}$ Regarding labor market history, we consider earnings and employment one month before migration as well as unemployment experience, earnings, number of past job changes and industry, measured 6,12 , and 24 months before migration. Paying particular attention to unemployment in the past is crucial because about 52 percent of migrants are unemployed before migration.

Our outcome variables of interest are earnings and unemployment at a monthly frequency. Earnings are defined as the daily wage for employed individuals and as zero for the unemployed. Thus, a change in earnings may reflect a change in on-the-job earnings or a change in the employment status. Real earnings are calculated in 2004 Euros using the aggregate consumer price index for Germany. Unemployment is measured as a binary variable. The sample used for the further analysis includes all individuals who have non-missing values in all control variables in the month before migration. Observations of individuals after entering retirement are excluded.

\section{Main Empirical Findings}

Figure 3 provides first graphical evidence on the evolution of earnings and unemployment for the three groups by month before/after migration (三treatment). Job changers and stayers are temporally aligned to the treatment month of migrants as described above. Since the results do not vary strongly across cohorts, we aggregate over the migration years 1994 to 2004. Figure 3 reveals that, before migration, earnings (unemployment) of migrants and job changers lie below (above) the level for stayers, which shows a negative selection of the

18 The list of covariates includes sex, age, education, tenure in the current/last firm (since 1992), number of job changes (since 1992), industry, occupation, total tenure in the industry of the last job (since 1992), current employment status, months in unemployment in the last 12 months, months in continuous unemployment $(0$ for the employed), share of time in unemployment since reunification, federal state of last job, type of position in last job, population/mean employment/mean earnings/distance to Western border of the district of the last job, and number of employees/median of earnings in the last firm. 
former two groups relative to stayers. In addition, there is a continuous and accelerating decline in earnings and employment among migrants and job changers before the treatment month. The strong increase in unemployment among migrants and job changers seems to be the main driver for the strong pre-migration dip in labor market outcomes. ${ }^{19}$ In contrast, earnings and employment among stayers remain fairly stable over time. The results suggest that a deterioration of the labor market situation in East Germany increases the migration propensity. Those who stay predominantly show a stable development over time, while the employment rate among prospective migrants drops dramatically right before migration. For this reason, we focus on the timing of migration and the pre-migration dynamics, especially regarding unemployment. The proximity of the developments for job changers and migrants shows that workers who change jobs/find a job in East Germany at the same time as migrants (in West Germany), show a similar decline in the labor market outcomes in the months before their job change.

Figure 3: Earnings and Unemployment without IPW
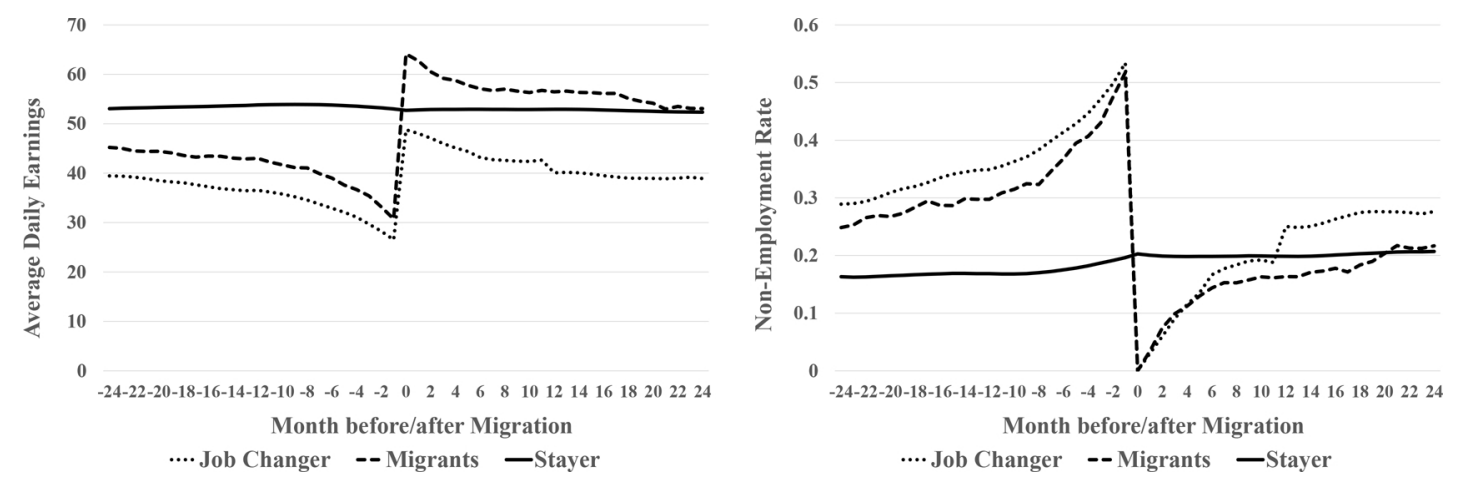

Notes:The figures show daily earnings (left) and unemployment rate (right) for job changers, migrants and stayers in relation to months before and after migration. Earnings are real average daily earnings in Euro and unemployment is the share of individuals who do not work among all individuals in the sample. Both measures are computed after temporal alignment for the three groups for the months - 24 to 24 before/after the treatment month but without applying inverse probability reweighting (IPW) to account for differences in observable characteristics between three groups. Population weights are used for all groups. Observations are excluded from the data if the individual enters retirement. Missing employment information are treated as unemployment.

Source: Own calculations based on BASiD 5109.

After treatment (from month zero onward), migration and job change are associated with a strong initial boost in employment and earnings. By definition, unemployment among migrants and job changers falls to zero in the treatment month, increasing average earnings for both groups. Migrants additionally benefit from the higher wage level in the West, which raises their average earnings above those of stayers, who already were in a substantially better labor market position before migration. With respect to the development over time after migration/job change, earnings for both migrants and job changers fall continuously during the first year after treatment, driven by the increase in unemployment. Both outcomes stabilize during the second year. The outcomes of stayers do not change much after treatment,

19 The earnings among employed migrants and job changers remain stable over time, but are also lower than those of stayers. 
showing a stable level over the four-year period considered, which reflects that the vast majority of stayers simply keeps their jobs.

While the descriptive evidence on the evolution of outcomes in Figure 3 can be used to study the pre-migration developments of the different groups, it is not informative about actual returns to migration. The group of stayers strongly differs from migrants with respect to individual characteristics and labor market developments before migration. To make job changers and stayers provide valid counterfactuals for migrants, we will reweight stayers and job changers towards migrants using IPW. This allows us to estimate the treatment effects of migration compared to the two counterfactuals and to assess if the estimated returns to migration depend upon the control group used.

\subsection{Estimated returns to migration}

We estimate the ATTs of migration-vs-staying and migration-vs-job-change by applying IPW, thus accounting for the selection of migrants with regard to differences in covariates and pre-treatment labor market history. The latter is particularly important in light of the premigration and pre-job-change dip in earnings and employment. ${ }^{20}$ Figure 4 shows the evolution of earnings and unemployment for the three treatment groups aggregated over all cohorts after IPW, showing that IPW is very successful in aligning earnings and unemployment prior to migration. ${ }^{21}$

Accounting for selection has a different effect for job changers and stayers (compare Figure 3 and Figure 4). The changes through re-weighting are not large for job changers. The differences compared to migrants decrease a bit, because job changers are more strongly negatively selected than migrants. From the definition of job changers, it follows that job changers provide the average counterfactual for migrants who would have found a job in East Germany at the same time when the migration occurred (in case of being unemployed before migration), or who would have changed jobs in East Germany instead of taking up a job in West Germany (in case of being employed before migration).

For stayers, the pre-migration trajectory is strongly affected by IPW re-weighting because now more weight is given to those stayers who experience a deterioration of their labor market outcomes. However, after the month of (potential) migration the curves differ in a substantial way. By definition of the comparison group (the alternative treatment to migration), stayers represent an average counterfactual among workers who are employed and unemployed at the time of potential migration, with gradual transitions between the two employment states

20 The results of logit regressions used for estimating the treatment probability are shown in Table 6 in the Appendix (for readability, results aggregated over all cohorts with cohort dummies are reported, while for the actual IPW weights, logit models are estimated for individual migration cohorts). Table 7 shows the means of the control variables (aggregated over all cohorts) by treatment group before and after reweighting. IPW proves very effective in equalizing the means of the control variables considered.

21 The results by calendar years are shown in Figure 16 in the Appendix. 

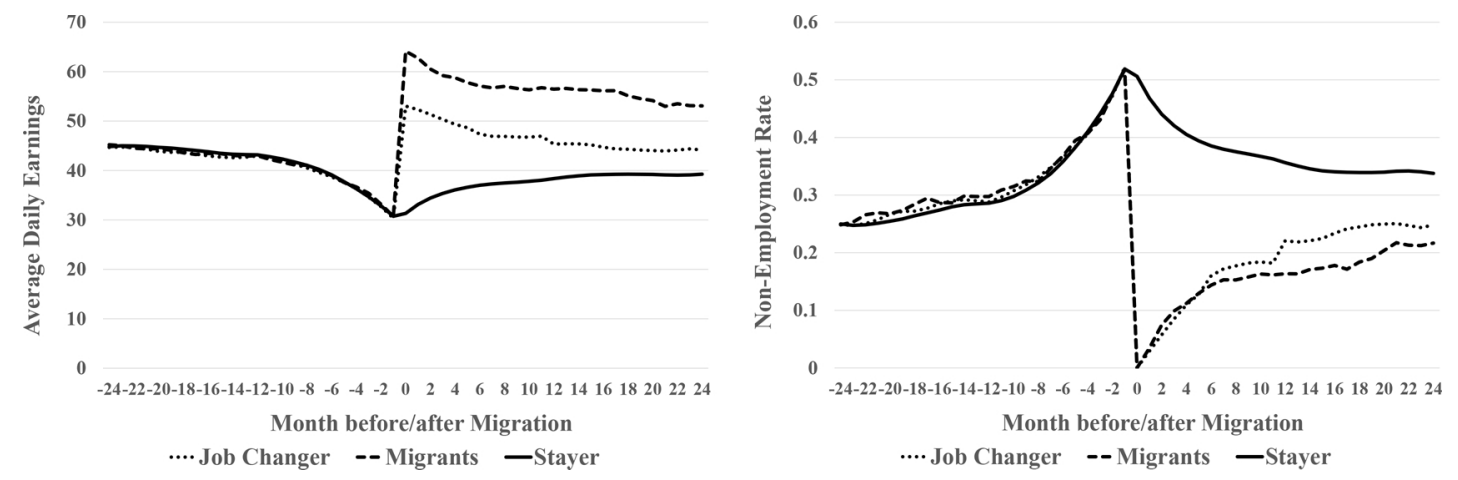

Notes: The figures show daily earnings (left) and unemployment rate (right) for job changers, migrants and stayers in relation to months before and after migration. Earnings are real average daily earnings in Euro and unemployment is the share of individuals who do not work among all individuals in the sample. Both measures are computed after temporal alignment for the three groups for the months - 24 to 24 before/after the treatment month. In addition, IPW is applied for job changers and stayers to account for differences in observable characteristics to the group of migrants. Population weights are used for all groups. Observations are excluded from the data if the individual enters retirement. Missing employment information are treated as unemployment.

Source: Own calculations based on BASID 5109.

afterwards. The slow increase of employment and earnings after the month of potential migration for stayers is driven by unemployed stayers finding a job, i.e. different unemployment durations among stayers who are unemployed at the time of potential migration, which is consistent with a standard job search model. The large initial gap in earnings between migrants and stayers is caused by the start of a job in the West at the time of migration and higher wages in the West, while unemployed stayers - in contrast to unemployed migrants and job changers - do not immediately start a job in period 0 . The partial convergence between migrants and stayers over time is due to falling employment differences as unemployed stayers find a job and some migrants become unemployed again. The aggregate developments thus show the importance of accounting for unemployment, pre-migration developments and the timing of migration. Ignoring these factors would have led to a comparison of migrants to a control group with different dynamic selection.

Figure 5 shows the ATTs of migration-vs-staying ( $A T T^{\text {Stay }}$ ) and migration-vs-job-change $\left(A T T^{J C}\right)$, which are the differences of the corresponding curves in Figure 4 . The differences before month 0 are almost never statistically significant. In month 0 , the jump in earnings among migrants implies a return of $A T T^{\text {Stay }}=33$ Euro in daily earnings (106 percent higher earnings) compared to stayers. However, returns strongly decline afterwards to around 14 Euros two years after migration (36 percent). The returns in daily earnings $A T T^{J C}$ compared to job changers are much smaller in month 0 , amounting to 11 Euros (20 percent). These returns fluctuate a bit afterwards but remain fairly stable over the post-treatment period corresponding to 9 Euros (20 percent) in month 24 . Both ATTs for earnings are significantly different from 0 for the entire 24 months after migration, and ATT Stay is always significantly higher than $A T T^{J C}$ (detailed results are available upon request). Regarding the ATT for the 
second outcome, unemployment of migrants in month 0 is 51 percentage points ( $\mathrm{pp}$ ) lower $\left(A T T^{\text {Stay }}=-51 \mathrm{pp}\right)$ than for stayers and the difference falls over time to $13 \mathrm{pp}$ in month 24 $\left(A T T^{\text {Stay }}=-13 \mathrm{pp}\right)$. While unemployment among migrants is similar to job changers during the first months, it is (significantly) lower during the second year and the absolute difference increases over time.

Figure 5: Causal Effects for Earnings and Unemployment (ATTs)
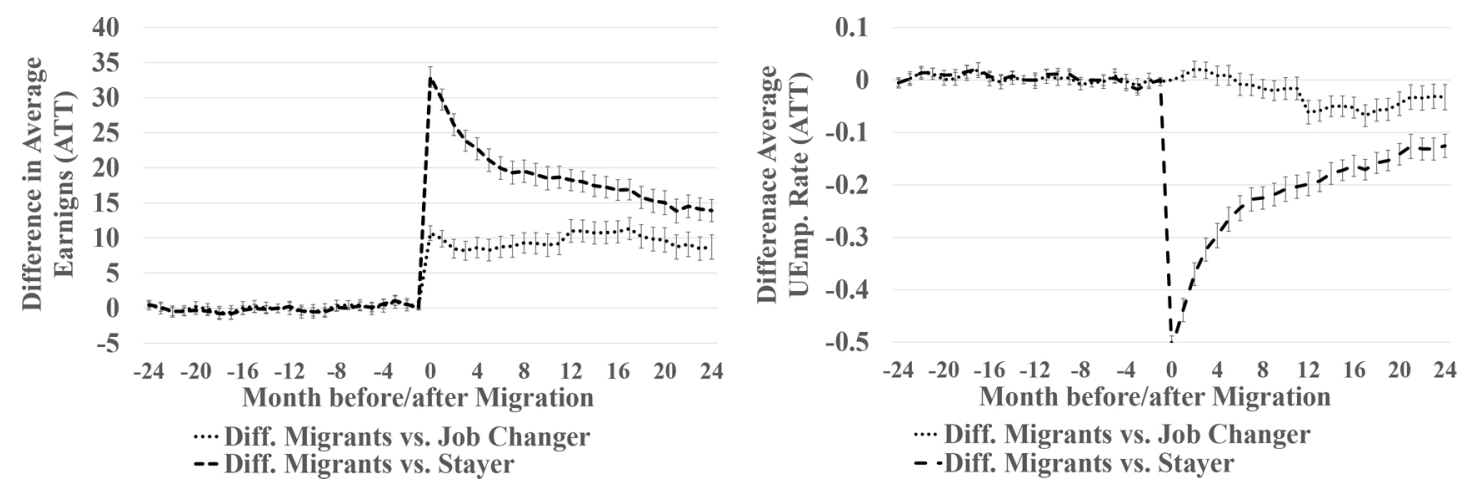

Notes: The figures show the average effects of treatment for the treated (ATTS), i.e. the average returns for the migrants, for earnings (left) and unemployment (right) based on the difference in aggregate outcomes displayed in Figure 4 after IPW has been applied. Confidence bands are calculated using bootstrapped standard errors clustered at the individual level.

Source: Own calculations based on BASID 5109.

Since migration shows significantly positive effects against both alternative treatments, the direction of the effect of migration versus non-migration is robust. At the same time, the stark differences between the two treatment effects $A T T^{S t a y}$ and $A T T^{J C}$ show the importance of the counterfactual in East Germany, confirming for our setting the concerns raised by Ham/ Li/Reagan (2011). When a new job is offered in East Germany, the returns to migration are lower and therefore less likely to exceed the individual costs of migration.

\subsection{Returns by Prior Employment Status}

Since unemployment plays a central role for the pre-migration developments and the size of returns to migration, we now provide disaggregated results based on the employment status before migration. The theoretical considerations in Section 3 presume that average earnings returns to migration are higher for those unemployed before migration than for those employed. We now investigate the validity of this by re-estimating the earnings returns to migration by employment status in the month before treatment. Recall that among migrants and job changers about 50 percent are unemployed in the month before treatment, while unemployment among stayers amounts to about 20 percent (Figure 3).

We divide each of our three treatment groups (migrants, job changers and stayers) into two subgroups based on their employment status in month -1 . For stayers, we have to address 
the difficulty that they do not experience a treatment event in a given year. Similar to the estimation of the ATT above, we replicate each stayer 12 times in a given year and assign each replication a different calendar month as treatment month. These 12 replicated stayers are then assigned to the "employed" or "unemployed" group based on the observed employment status in the month before the assigned treatment month.

Now, we re-estimate the earnings profiles separately for the subgroups defined by the employment status using IPW after temporal alignment. ${ }^{22}$ The results are displayed in Figure 6 , to the left for those unemployed in -1 and to the right for those employed in -1 . The estimated profiles differ strongly for the two subgroups. For unemployed migrants/job changers/stayers, earnings show qualitatively very similar profiles compared to the results in Figure 4 for the entire sample, with a steeper decline before treatment and a larger jump for migrants and job changers upon migrating/job changing. In contrast, the profiles for the employed sample are very stable over time.

The initial ATTs compared to job changers are comparable irrespective of the employment status before treatment, with $A T T^{J C}$ equal to around 11 Euros in the "unemployed" and "employed" sample. However, the estimates diverge over time, with the $A T T^{J C}$ after 24 months being 11 Euros for the unemployed and 7 Euros for the employed sample. This is because the earnings of job changers who were employed before job change are more stable than the earnings of job changers who find a job after a spell of unemployment, whereas the pre-migration employment status matters for the earnings level of migrants, but not so for the earnings dynamics after migration.

The results are very different when comparing migrants and stayers. Migrants from unemployment can realize an initial gain (ATT ${ }^{\text {Stay }}$ ) of 50 Euros compared to stayers who are unemployed. In contrast, the ATT Stay is only 14 Euros compared to employed stayers. The large difference arises through the higher employment rate (after migration) of migrants from unemployment compared to unemployed stayers. Migrants who are employed before migration don't gain that much compared to employed stayers. The difference in migration returns shrinks over time (the ATT ${ }^{\text {Stay }}$ in month 24 is 20 Euros when unemployed and 8 Euros when employed before migration). This is due to employment growth among formerly unemployed stayers which reduces the gap to migrants over time. Altogether, the results show that there are sizeable migration returns irrespective of the employment status before migration, that there is not much difference in the developments for the different control groups when only workers who are employed in month -1 are considered, and that the large aggregate migration returns compared to stayers are driven by those migrants and stayers who are unemployed before treatment.

22 Due to sample size issues in certain cases for the employed, IPW for the years of 2003 and 2004 for the control group of job changers and for the years 1994 and 1995 for the control group of stayers is based on logistic regressions using data from both years, with year dummies as additional controls. 
(a) Unemployed before Migration (IPW)

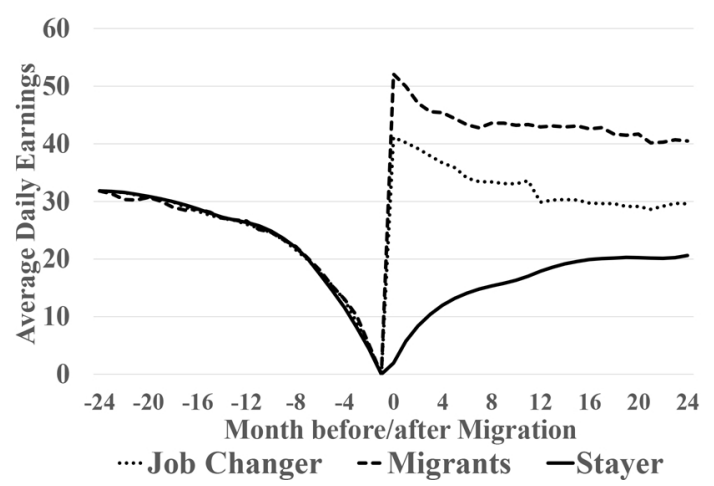

(b) Employed before Migration (IPW)

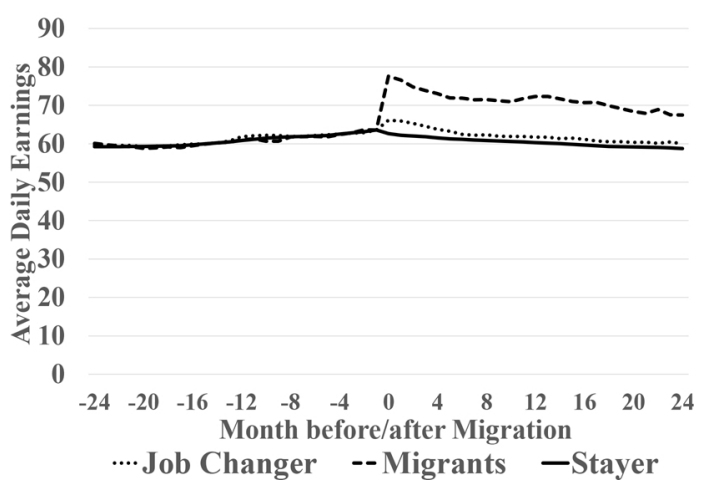

Notes: The figures show average daily earnings for job changers, migrants and stayers in relation to months before and after migration after population weights and IPW have been applied. The results for the three treatment groups are presented for two sub-populations, those who were unemployed in the year before the treatment month (conceptually stayers are replicated 12 times and assigned different treatment months and those who are unemployed in the month before the hypothetical treatment month are assigned to the group of the unemployed) are displayed on the left and those who are employed in the month before the treatment month are displayed on the right. Average earnings and IPW are estimated separately for the two sub-populations.

Source: Own calculations based on BASID 5109.

\subsection{Additional Heterogeneity in Returns}

So far, we have discussed the returns to migration aggregated across all migrants or by employment status. Now, we further investigate the heterogeneity of returns with regard to other important characteristics. This can provide some evidence for group-specific variations in returns to migration, which should be connected to the migration propensity if they are informative about variations in returns to migration for non-migrants as well. For this purpose, we follow earlier work in Fitzenberger/Sommerfeld/Steffes (2013) and estimate weighted outcome regressions

$Y_{i a}=\alpha+x_{i} \beta+\gamma_{a} T_{i}+T_{i}\left(x_{i}-\bar{x}\right) \delta_{a}+u_{i a}$

for period $a=-24, \ldots, 24$ relative to migration, where $Y_{i a}$ are earnings, $T_{i}$ the treatment (migrant) dummy, $x_{i}$ are control variables and $\bar{x}$ is the sample average among the treated. The regressions are estimated based on migrants and non-migrants aligned in time. Migrants carry a weight of one and the non-migrants are re-weighted according to the IPW (for further details see Fitzenberger/Sommerfeld/Steffes (2013)). $\delta_{a}$ measures the heterogeneity in treatment effects for different values of the control variables. The ex post outcome regression in equation (6.1) also accounts for differences in control variables between treated and non-treated remaining after IPW. The regressions reveal two important control variables that cause heterogeneity in returns to migration, namely gender and earnings before migration. ${ }^{23}$ We now discuss graphical evidence on the differences in treatment effects when grouping the

23 Regression results are not reported here, but available upon request. 
data by these control variables, analogous to the approach in section 6.2, but based on an outcome regression for the entire sample (instead of separate regressions for sub-samples).

Figure 7 shows the ATTs by gender - and for comparison for the entire sample. The returns to migration, both versus staying and versus job change, prove to be higher for males than for females, reflecting the fact that the gender pay gap is higher in the West than in the East (this is confirmed by running separate earnings regressions with a gender dummy for the West sample and the East sample). The absolute and relative gender gap in returns is higher for $A T T^{J C}$ than for $A T T^{\text {Stay }}$. Still, the returns to migration are significantly positive for both genders, and female migrants realize substantial earnings gains relative to stayers.

Figure 7: Heterogeneity in ATT based on Gender
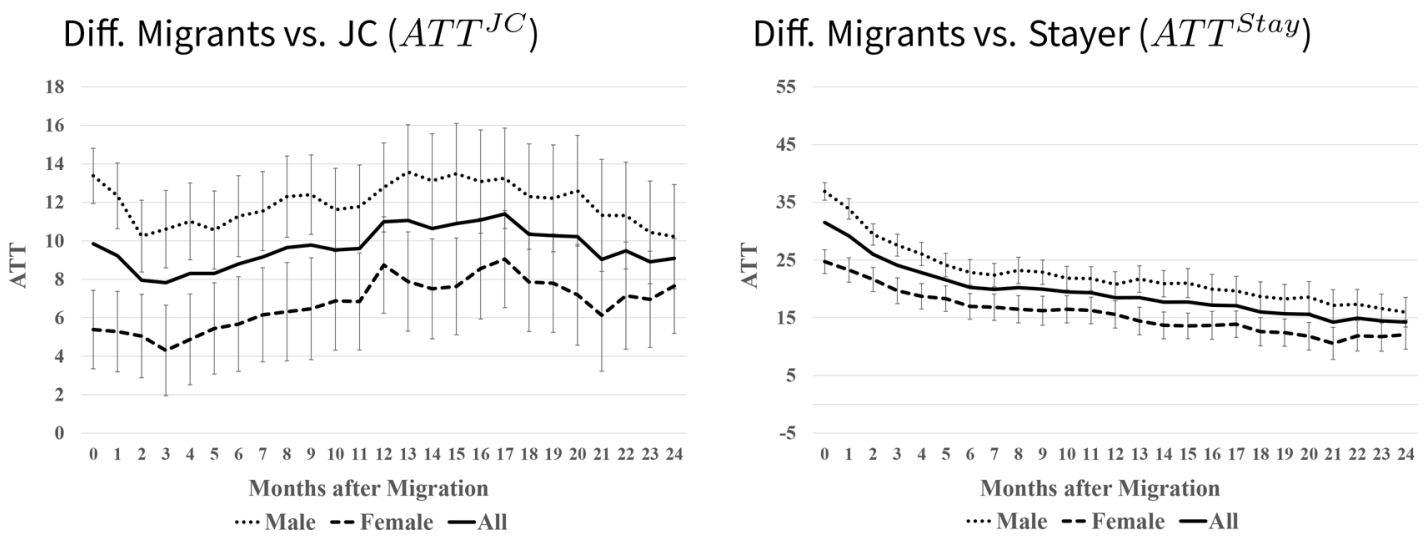

Notes: The figures show the average effect of treatment for the treated for males and females in relation to months after migration. Results display heterogeneity in ATTs for average daily earnings depending on gender compared to job changers (left) and stayers (right) based on outcome regressions as introduced in the text. ATT aggregated over the two genders are presented as "All". Aggregated ATT might differ slightly from the ATT presented in Figure 5, due to the additional equalization of control variables after month-1 through outcome regressions and due to less strict temporal alignment (instead of computing monthly ATTs and then aggregating over months and years, month and year dummies are used in the outcome regressions). Confidence bands are based on bootstrapped standard errors, clustered on the individual level. No confidence bands for the aggregated ATTs are shown to increased readability and since significance of group differences is of primary interest. Source: Own calculations based on BASiD 5109.

We now turn to the ATTs by earnings before migration (in month -1) displayed in Figure 8. To account for unemployment (zero earnings), we consider three groups, namely no earnings (unemployed in month -1), positive earnings below/at the median in -1, and positive earnings above the median in -1 , where the median is based on the sample with positive earnings. There is substantial heterogeneity, especially for $A T T^{\text {Stay }}$. For $A T T^{J C}$, the differences are mostly not statistically significant (the figure to the left omits the large confidence intervals to avoid confusing the lines). The returns to migration are similar for those with no earnings or low earnings in -1, and they are higher in both cases than for those with high earnings in -1. Turning to $A T T^{\text {Stay }}$, the differences are larger and mostly significant. The returns to migration are highest for those with no earnings in -1 and lowest for those with high earnings in -1 . Because earnings are measured in Euros, the differences in relative returns among those with positive earnings are even more striking. The evidence is consistent with a limited transferability of human capital from the East to the West for higher-earners or limited access of East 
German migrants to high-paying jobs in the West. ${ }^{24}$ Sorting out these different explanations is beyond the scope of this paper.

Figure 8: Heterogeneity in ATT based on Earnings in East Germany
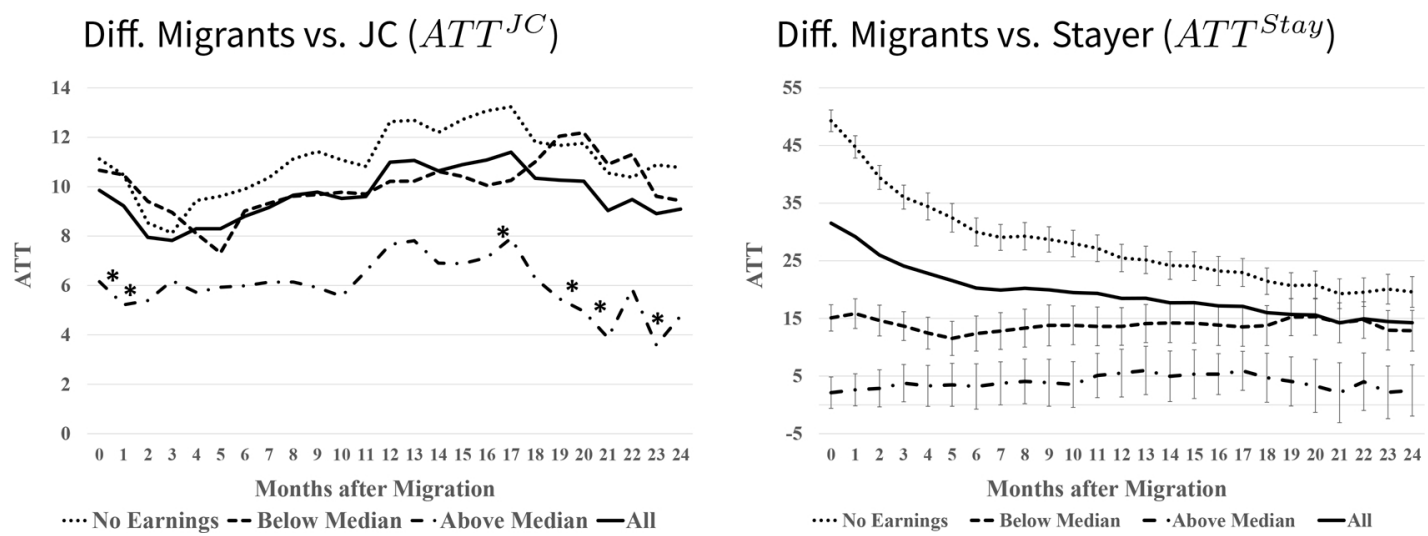

Notes: The figures show the average effect of treatment for the treated in relation to months after migration for three groups defined based on earnings before migration. Results display heterogeneity in ATTs for average daily earnings compared to job changers (left) and stayers (right) based on outcome regressions as introduced in the text. Heterogeneity here is based on earnings in East Germany in the month before the treatment month. Individuals who are unemployed one month before treatment are assigned to the "No earnings" group. The median of all positive earnings one month before migration is calculated and individuals with positive but below median/median earnings are assigned to the "Below Median" group and individuals with above median earnings are assigned to the "Above Median" group. ATT aggregated over the different income groups are presented as "All". Aggregated ATT might differ slightly from the ATT presented in Figure 5, due to the additional equalization of control variables after month -1 through outcome regressions and due to less strict temporal alignment (instead of computing monthly ATTs and then aggregating over months and years, month and year dummies are used in the outcome regressions). Confidence bands are based on bootstrapped standard errors, clustered on the individual level. Confidence bands for the comparison of migrants and job changers are suppressed to allow readability. The confidence bands for the ATT's for migrants-vs-job changers with no earnings or below median earnings before migration/job change always overlap. For migrants-vs-job changers with above median earnings before treatment, confidence bands of the ATT do not overlap with the confidence bands of the ATT of migrants-vs-job changers with no previous earnings before treatment in months 0,1,16,19-21 and 23 and do not overlap with the confidence bands of the ATT of migrants-vs-job changers with below median earnings before treatment in months 5 and 19-21.

Source: Own calculations based on BASiD 5109.

In sum, there is strong evidence that the returns to migration are higher for individuals with lower earnings potential in the East and that returns for men are larger than for women. This is in line with lower migration rates for women and for high-earners in East Germany.

\section{Robustness Checks}

\subsection{Distance of Migration}

As a first robustness check, we want to investigate whether our aggregate results are driven by migrants who commute to West Germany from East German districts close to the East-

24 In addition, Prantl/Spitz-Oener (2019) show that the effects of East-to-West migration on native wages as well as the wage gap between East German migrants and West German incumbent workers depended on the degree of product and labor market regulations in different segments of the West German labor market. Returns to migration might thus also have varied across these different segments. 
West German border. These migrants might be a specific selection of the East German work force, because they are likely to incur lower migration costs. ${ }^{25}$ Unfortunately, we do not observe commuter status in our data. To test whether our aggregate results are driven by commuters, we exclude all short-distance migrants from our sample, for whom the distance between the location of their last job and the first job after migration is less than 100 kilometers. These short-distance migrants are likely to include almost all daily commuters. The distance is based on the distance between the capital of the two districts in East and West Germany, respectively. The share of short-distance migrants among all migrants is only 21 percent. Figure 9 shows the results for migration returns when the short-distance migrants are excluded. It is evident that the results only change marginally, indicating that our results are not driven by different outcomes for short-distance migrants.

Figure 9: Causal Effects for Earnings with and without short-distance Migrants (ATTs)

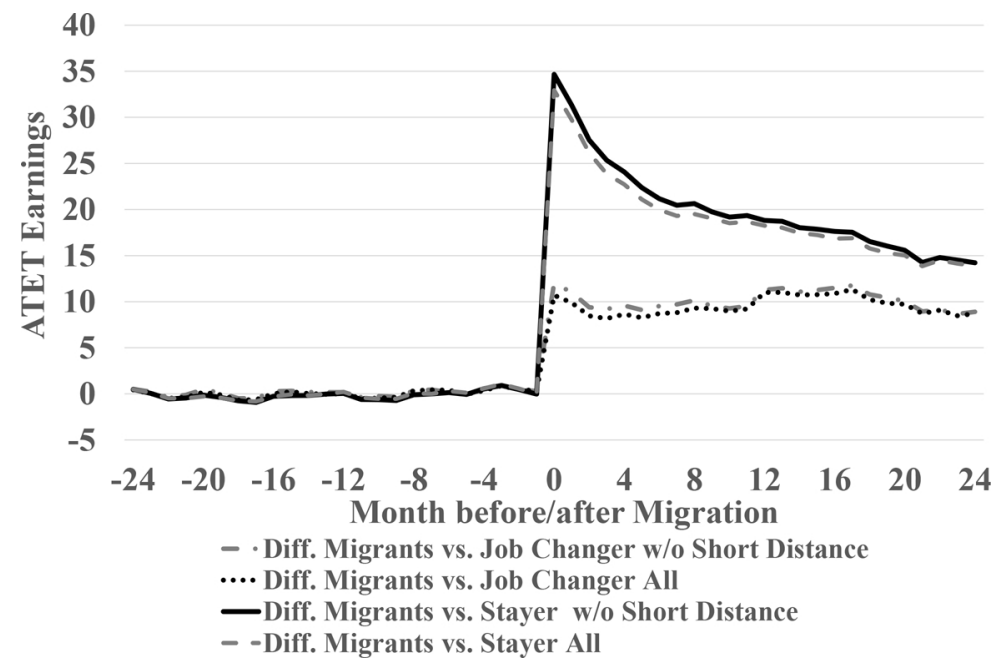

Notes: The figure shows the differences in average daily earnings of migrants in relation to months before and after migration when excluding short-distance migrants and after population weights and IPW have been applied. The results for all migrants are the same as in Figure 5. Results for the sample without short-distance migrants are based on all migrants for whom the location of last job before migration and first job after migration is more than 100 kilometres apart. The displayed results are the differences between earnings of migrants and job changers and stayers respectively.

Source: Own calculations based on BASiD 5109.

\subsection{Regional Price Differences}

There are persistent regional differences in the cost of living in Germany. Prices are lower in the East than the West and in rural areas compared to urban areas. As a robustness check, we investigate whether returns to migration are still positive after accounting for regional price differences. While migrants on average take up a job in more expensive regions (urban

25 Note that one of the control variables used to estimate the IPW is distance to West Germany of the district where the last job of a migrants before migration was located in East Germany. 
districts in the West), we do not expect sizeable changes in the cost of living for stayers and job changers. We expect the estimates accounting for regional price differences to provide lower bounds of the returns to migration because migrants (especially commuters) are likely to spend a sizeable share of their income in the less expensive source region.

We have to address the problem that there are no consistent time series of regional price indices at the district level, the finest regional unit in our data. 2009 is the first year for which relative price differences across districts are provided by the Bundesinstitut für Bau-, Stadtund Raumforschung (BBSR). We extrapolate the 2009 regional price index (RPI) at the district level back to earlier years using price indices supplied by the Federal Statistical Office for the German states (Länder) from the year 1995 onward as well as the differential price indices in East and West Germany for the years 1992 to 1995 (Vortmann et al., 2013). ${ }^{26}$ Due to potential limitations of our regional price index and the uncertainty about how much migrants spent in the East and the West, we refrain from using the RPI for our main estimates.

Figure 10 contrasts the effect of migration on real earnings after IPW based on the aggregate $\mathrm{CPI}$ as above ('Original' in graph) and based on the regional price index (RPI). ${ }^{27}$ After accounting for the RPI, the estimated effects of migration on earnings are reduced, as expected, because of the lower cost of living in the East. However, the effects of migration on real earnings remain strongly positive and show the same time profile as for the estimates based on the aggregate CPI. For instance, after accounting for the RPI, $A T T^{J C}$ amounts to 7 Euros (12 percent) and $A T T^{\text {Stay }}$ to 29 Euros (94 percent) in month 0 . Thus, the direction of our main effect estimates is robust when accounting for regional price differences.

\subsection{Comparison to Standard Estimators}

Our dynamic treatment approach stresses the importance of aligning detailed labor market histories before migration in the presence of a pre-migration dip. Such a pattern invalidates standard difference-in-differences (DiD) approaches (Heckman/Smith (1999)) and requires data at a monthly frequency. Next, we investigate whether our methodological considerations change the earnings effects of migration in comparison to standard estimators used in the literature. First, we implement standard DiD estimators of the effect of migration. Second, we redo our analysis based on data at the annual frequency. Figure 11 shows the results of both exercises.

To implement the DiD approach based on monthly data, we run panel OLS regressions with individual fixed effects $\alpha_{i}$ and year fixed effects year ${ }_{y(j)}$ for individual $i$ and time period $j$. We

\footnotetext{
26 There are no price indices for the states Bremen, Hamburg, and Schleswig-Holstein, for which we use the price index for Lower Saxony (the closest large neighbouring state).

27 The city of Bonn is the reference for the RPI in 2009 (RPI=100 for Bonn). To ensure comparability with and without RPI, we take stayers (the largest group) as our reference group and compute the ratio between the real earnings with and without accounting for RPI at month -1 . Then earnings after deflation by RPI are divided by this ratio, thus using the stayer average in East Germany as new reference level.
} 


\section{Figure 10: Causal Effects for Earnings with and without RPI (ATTs)}

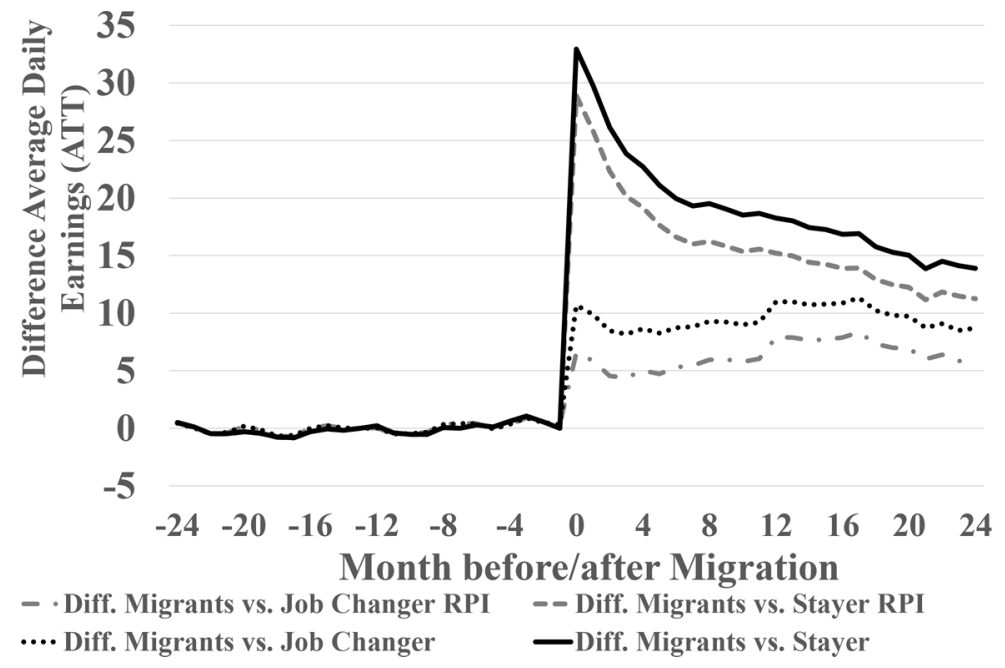

Notes: The figure shows the differences in average daily earnings for migrants in relation to months before and after migration when adjusting for the regional price index and after population weights and IPW have been applied. Results without RPI are re-estimated, since the sample slightly changed, due to (very few) observations not having information on the district of work. Results with RPI are computed by first multiplying stayer earnings with the RPI and then estimating average monthly earnings of stayers after population weights and IPW have been applied. These results are then divided by the average earnings of stayers after population weights and IPW but without RPI. Earnings are then divided by these monthly ratios, yielding earnings after application of the RPI. The displayed results are the differences between earnings of migrants and job changers and stayers respectively.

Source: Own calculations based on BASiD 5109, BBSR and the German Statistical Office. 
also add calendar month fixed effects mont $_{m(j)}(m \equiv$ Jan, Feb etc.) to account for seasonality. Specifically, we estimate the following two regressions where the first estimates the $A T T^{\text {Stay }}$ based on the migrant-stayer sample and the second estimates the $A T T^{J C}$ based on the migrant-job-changer sample:

$$
\begin{aligned}
& Y_{i j}=\alpha_{i}+\text { year }_{y(j)}+\text { month }_{m(j)}+T_{i j} \sum_{a=0}^{24} \beta_{a} I[a(i, j)=a]+\epsilon_{i j} \\
& Y_{i j}=\alpha_{i}+\text { year }_{y(j)}+\text { month }_{m(j)}+\sum_{a=0}^{24}\left(T_{i j} \beta_{a}+\gamma_{a}\right) I[a(i, j)=a]+\epsilon_{i j}
\end{aligned}
$$

$Y_{i j}$ are earnings, $T_{i j}$ is the migration dummy (=1 after migration), $a(i, j)$ is the number of month since migration (job change), and $I[$.$] is the indicator function. The specification (JC)$ allows for a differential effect $\gamma_{a}$ of time since job change in the control group of job changers, because job changers experience a transition in month 0 , whereas such an effect plays no role for stayers who comprise a mix of different employment and unemployment durations at any point of time. The individual fixed effects capture the pre-migration differences between migrants and the comparison group. Thus, $\beta_{a}$ are the DiD estimates of the earnings effect of migration by month $a$ since migration.

The DiD estimates for migration-vs-job-change displayed in Figure 11 (graph to the left) are quite similar to the IPW results in Figure 5. This is because job changers and migrants have a similar pre-treatment history, which is consistent with the common trends assumption needed for DiD. However, for stayers, the DiD estimates in Figure 11 (graph to the left) differ in a substantial way from to the IPW results in Figure 5. The DiD estimates are downward biased, especially during the first year after migration, when taking our IPW estimates as benchmark. Here, the common trends assumption is not fulfilled because of the pre-migration dip in earnings. Since DiD averages the pre-treatment outcomes before migration, the method does not account for the strong pre-migration dip in earnings.

As the second comparison, the graph on the right in Figure 11 provides IPW estimates based on annual data. Here, we only use the December information, thus discarding the data from January to November of the same calendar year. We still use those control variables which are based on monthly information (e.g. duration of unemployment) because such variables may be available based on retrospective information in data sets with annual data. The treatments migration and job change are now defined based on the event taking place at some point in time within a calendar year. We now align individuals in time based on the yearly information (e.g. year=-1 denotes "1-12" month before migration, year=0 "0 - 11" months since migration) and we use IPW to account for differences in other characteristics. Our findings for year 0 imply an $A T T^{J C}$ of 8 Euros (17 percent) and an $A T T^{\text {Stay }}$ of 14 Euros (33 percent). Simply averaging over the first 12 months after migration of our IPW estimates using monthly data yields returns of 9 Euros versus job change and 23 Euros versus staying. ${ }^{28}$ Thus, the analysis

28 These are even lower bounds because returns to migration decline over time, and migrants in year 0 have migrated between 0 and 11 months before. 
Figure 11: Estimated Causal Effects for Earnings using Difference-in-Differences or using Yearly Data
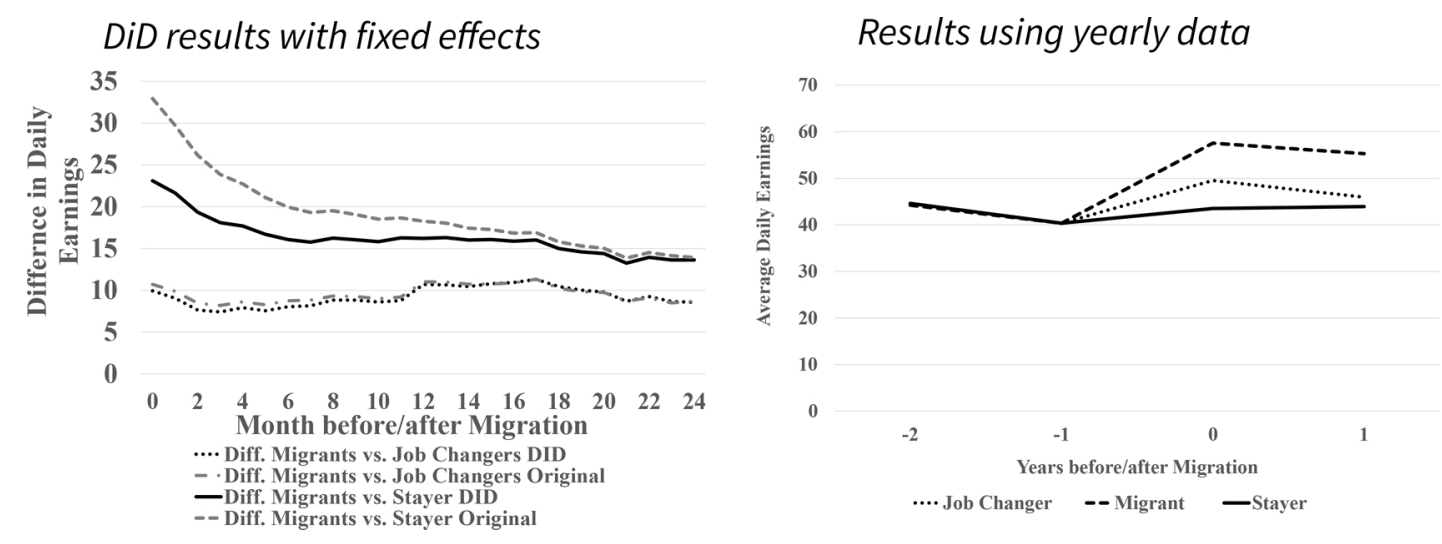

Notes: The figures show the effects on daily earnings of migrants in relation to months before and after migration obtained using the differencein-differences method (left) and to years before and after migration (right) using yearly data. DiD results for earnings are based on the fixedeffect Difference-in-Difference method introduced in the text and compared to ATT estimates obtained through IPW as in Figure 5. Earnings based on yearly data use the same IPW method as before but now only use information from December instead of information from the whole year. Migrants are defined as individuals who change the location of their work between December of a specific year and December the year before. In parallel, job changers are individuals who work for a different employer in East Germany compared to one year before. Stayers or those who remained in their work or remained unemployed compared to the previous December. Thus migrants who migrated after the previous December but returned before the current December are not counted as well as job changers who lost their new job already before the current December.

Source: Own calculations based on BASiD 5109.

based on annual data severely underestimates the returns to migration, especially in comparison to stayers. Again, this is because using data at the annual frequency does not account for the pre-migration dip in earnings.

\section{Migration Barriers and Expectations}

In light of the strong positive returns to migration, especially among individuals with low earnings potential in the East, the question arises why migration is not higher in the absence of legal restrictions or language/cultural differences. Using survey data from the SOEP, we thus explore possible barriers to migration, and we investigate the importance of expectations about future labor market opportunities in the East.

The literature discusses different factors which may prove to be barriers to migration. Rosen (1972) and Roback (1982) analyze the role of amenity differences. Bound/Holzer (2000), Chiquiar/Hanson (2005), and Wozniak (2010) point to differences in financial and psychological costs as determinants of migration. Heise/Porzio (2019) document by revealed prefer- 
ences that East Germans are willing to incur large wage penalties for staying in the East compared to working in the West because of locational preferences ("home-bias"). Behavioral economics emphasizes the role of personality traits and attitudes for economic decision making. Jaeger et al. (2010) find that migrants are on average less risk-averse than non-migrants and Canache et al. (2013) show the impact of personality traits on the emigration decision. Caliendo et al. (2019) show that individuals with internal locus of control are more likely to migrate.

Since the BASiD lacks information to further investigate these channels, we turn to survey evidence from the SOEP. The big shortcoming of the data set is its small size: Among the 4690 adults in East Germany in 1990, there are only 95 migrants between 1994 and 2004 who fit our treatment definition. However, the SOEP contains information on various factors not available in BASiD. To ensure comparability with our analysis of returns, we use similar definitions of migrants, job changers, and stayers, the same sample years, the same control variables (as far as they are available), and IPW to account for differences in observables. The main differences are: (i) with yearly data no temporal alignment at the monthly frequency is possible, (ii) less information on district and firm, (iii) a logit model pooled over all years is estimated because of the low number of migrants (including dummies for year and month of interview), and (iv) migrants from East to West Berlin are included.

Figure 12 shows the evolution of earnings before and after migration (earnings are earnings in the month before the interview and time is measured in years before/after migration). The SOEP findings are qualitatively similar to the findings based on BASiD, subject to the fact that the SOEP does not provide monthly data. Before treatment, migrants and job changers are negatively selected in earnings compared to stayers. ${ }^{29}$ Earnings of both job changers and migrants show an initial upward jump after job change/migration and a decline afterwards.

In the following, we document substantial differences in various proxies for moving costs, behavioral barriers, and economic expectations between the three groups. When these characteristics are included as controls when estimating IPW, earnings differences between the groups after IPW has been applied do not change in a substantial way. This provides evidence that these characteristics affect the migration decision without affecting labor market prospects in East Germany after treatment (results are available upon request), thus supporting our above findings based on the BASiD data lacking the characteristics considered here.

${ }^{29}$ Other studies (e.g. Hunt (2006) or Fuchs-Schündeln/Schündeln (2009)) find a positive selection of East-toWest migrants using the SOEP, which is likely to be caused by the different definition of the migrant group. Recall, that we only consider migrants with work experience during GDR times who have lived in the East until migration. Additionally we only consider migrants who report a change of jobs since the last interview to avoid misclassification. Without the last restriction, migrants are only slightly negatively selected. 
Figure 12: Monthly Earnings in the SOEP without (left) and with (right) IPW
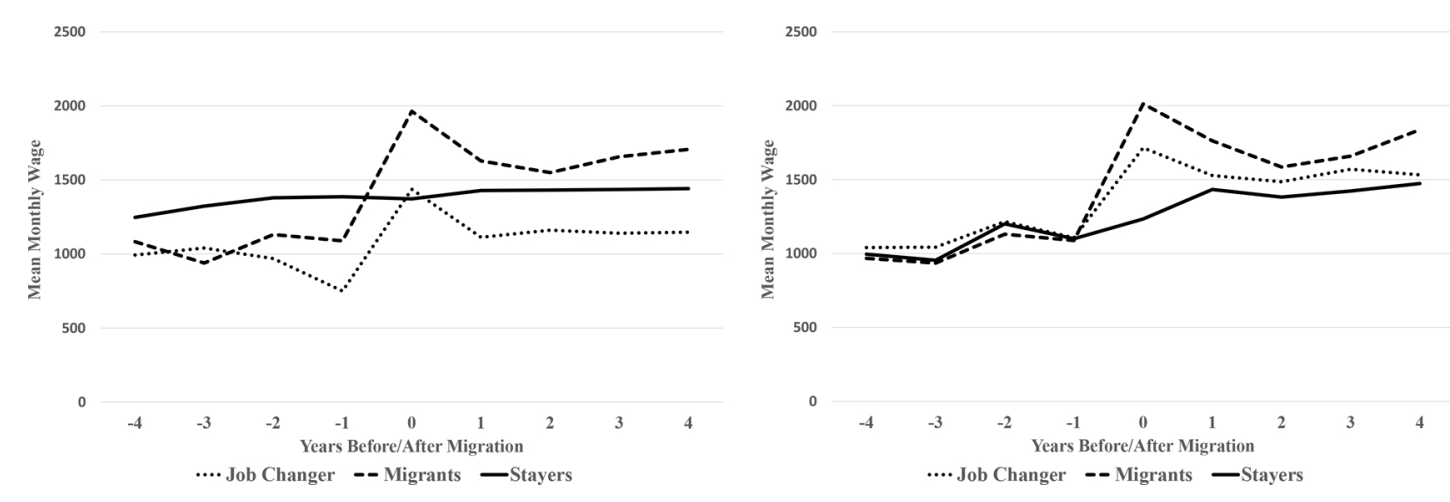

Notes: The figures display average monthly earnings before and after migration for job changers, migrants and stayers. Earnings are based on yearly data, where the interview was conducted in different month but mostly in spring/summer. Migrants are defined as individuals whose stated place of work in the last interview was East Germany and is West Germany in the subsequent interview. In parallel, job changers are individuals who work for a different employer compared to one year before. Stayers or those who remained in their work or remained unemployed compared to the previous interview. Thus migrants who migrated after the previous interview date but returned before the subsequent interview are not counted as well as job changers who lost their new job already before the subsequent interview. The graph on the left shows the results for the three groups with population weights but without IPW. The graph on the right shows results after IPW has been applied. The time unit is years before/after the treatment period (years can last slightly shorter/longer than 12 months since subsequent interviews are not always conducted in the same month).

Source: Own calculations based on SOEP v30.

\subsection{Financial and Psychological Costs}

First, we consider four proxies for psychological or financial costs of migration, which are often used in the literature: Marital status and number of children, owning a house in the East (Zaiceva (2006) uses this variable as an instrument for migration to the West), and knowing someone who moved to the West (family, friend, colleague). Table 2 provides means of the four proxies after IPW reweighting in the year before migration. Migrants are less often married, have less children, and less often own a house, indicating lower cost of migration. However, migrants as often know a person who moved to the West as stayers and less often than job changers. The latter finding may be explained by the fact that this question was asked only in 1991 and thus had to be extrapolated. In sum, the evidence on the first measures suggest lower migration costs among migrants.

\subsection{Risk Aversion and Attitudes towards Migration}

The SOEP elicits risk aversion in 2004 for the first time. Assuming stability over time, we extrapolate risk aversion back to the time of migration (1994 to 2004). Further, we consider the attitude to regional mobility and the attachment to the place of living, which are elicited in the SOEP for the years 1991 to 1999 . Table 3 provides evidence on these factors in the year before migration after IPW. In accordance with findings in the literature, migrants show lower risk aversion (the higher the number the less risk averse the individual), and a higher willingness to move than stayers, with the attitudinal differences being quite substantial. Migrants 
Table 2: Moving Costs

\begin{tabular}{lccc}
\hline \hline & \multicolumn{3}{c}{ Groups } \\
& Migrants & Stayer & Job Changer \\
\hline \hline Married & $44 \%$ & $62 \%$ & $68 \%$ \\
$\mathrm{~N}$ & 95 & 12784 & 1408 \\
\hline Number of Children & 0.71 & 0.98 & 0.97 \\
$\mathrm{~N}$ & 95 & 12812 & 1412 \\
\hline Own Property & $21 \%$ & $29 \%$ & $36 \%$ \\
$\mathrm{~N}$ & 95 & 12809 & 1412 \\
\hline Know someone & & & \\
who moved to the West & $32 \%$ & $35 \%$ & $32 \%$ \\
$\mathrm{~N}$ & 90 & 12358 & 1356 \\
\hline \hline
\end{tabular}

Notes: The displayed sample sizes refer to the number of individuals in the data that the values are based on. All results are weighted by population weights and the results for job changers and stayers are reweighted to reflect the distribution of control variables among migrants. Results refer to the year before migration/job change for migrants and job changers. For stayers, each year between 1993 and 2003 is counted.

Source: Own calculations based on SOEP v30.

also show lower attachment to their place of living than stayers and job changers and this even intensifies when migrants within Berlin are excluded (such a lower attachment is also found by Fuchs-Schündeln/Schündeln (2009)). It is conceivable that shocks before migration influence the migration decision as well as the willingness to move. In the years -4 to -2 , the willingness to move for migrants is indeed closer to non-migrants, but migrants still show a higher willingness to move (see Table 10 in the Appendix), indicating long-term attitudinal differences.

\subsection{Expectations and Worries}

The SOEP includes a number of variables on expectations and worries about the individual's economic situation in the East. East Germans were asked as to how much they worry about their economic future. Additionally, all employed East Germans were asked if they worry about losing their job, if they expect to be unemployed in the next two years, and if they expect to voluntarily search for a new position in the next two years. The worries were elicited every year between 1990 and 2015, whereas expectations at least every second year. ${ }^{30}$

Migrants are less optimistic about the future in general than job changers and stayers (Table 4). ${ }^{31}$ They are also slightly more worried about their economic situation than stayers, with 31

\footnotetext{
30 After 1998, answers to the expectation questions were not elicited in four categories as before, but rather as a (percentage) probability. To maintain the categorical structure and make it more comparable to the worries questions, probabilities were grouped into four categories with 0-20 percent corresponding to "Surely not", 30 50 percent to "Rather unlikely", 60-80 percent to "Likely" and 90 - 100 percent to "Surely".

31 This is in contrast to Fuchs-Schündeln/Schündeln (2009), who find migrants to even be more optimistic than stayers. The study argues that this optimism is rather a measure for general outlook on life than a measure for the expectations about outcomes in East Germany during the years to come.
} 
Table 3: Behavioral Variables

\begin{tabular}{lccc}
\hline \hline & \multicolumn{3}{c}{ Groups } \\
& Migrants & Stayer & Job Changer \\
\hline \hline Risk Aversion & 5.12 & 4.87 & 5.04 \\
N & 75 & 10164 & 114 \\
\hline Attachment to Place of Living & & & \\
Very Strong & $25 \%$ & $31 \%$ & $22 \%$ \\
Strong & $50 \%$ & $44 \%$ & $61 \%$ \\
Weak & $23 \%$ & $21 \%$ & $15 \%$ \\
None & $2 \%$ & $4 \%$ & $2 \%$ \\
N & 64 & 7281 & 916 \\
\hline Conceivable to move away & & & \\
(job- or family-related) & & & \\
Yes & $53 \%$ & $25 \%$ & $19 \%$ \\
Depends & $31 \%$ & $36 \%$ & $44 \%$ \\
No & $15 \%$ & $39 \%$ & $37 \%$ \\
N & 73 & 8856 & 1108 \\
\hline Conceivable to move & & & \\
to the West & & & \\
Yes, gladly & $5 \%$ & $29 \%$ & $11 \%$ \\
Under some circumstances & $77 \%$ & $57 \%$ & $59 \%$ \\
Rather not & 59 & 4380 & \\
Definitely not & & & \\
N & & & \\
\hline \hline
\end{tabular}

Notes: The displayed sample sizes refer to the number of individuals in the data that the values are based on. All results are weighted by population weights and the results for job changers and stayers are reweighted to reflect the distribution of control variables among migrants. Results refer to the year before migration/job change for migrants and job changers. For stayers, each year between 1993 and 2003 is counted.

Source: Own calculations based on SOEP v30. 
percent being very worried and 58 percent having some worries (compared to 30 percent and 56 percent for stayers respectively), and job changers are even more worried than migrants and stayers.

Migrants and job changers are also more worried about job safety than stayers and expect more often to search for a new job, while the evidence on job loss expectations is less clearcut (the share of "likely" or "surely" is considerably higher among migrants and job changers, however, the share of those who state "surely not" is also higher). In sum, after accounting for differences in observables including past labor market outcomes in the East using IPW, the evidence points towards the conclusion that worries about one's own economic situation in the East and the perceived need to find a new job are drivers of migration.

\section{Conclusions}

This paper estimates the labor market returns of migration from East to West Germany in the aftermath of German reunification based on BASiD, a rich administrative panel data set. We focus on the second wave of migrants from East to West Germany in the aftermath of reunification among those who had already been employed before reunification and who had been staying in the East for some time after reunification. To estimate the average treatment effect on the treated of migration-versus-staying and migration-versus-job-change, we use a treatment approach which involves a temporal alignment of migrants to those not having yet migrated and which conditions on a rich set of observable covariates including lagged labor market outcomes. This approach yields the returns to migration at a certain point of time and entails the possibility that non-migrants migrate later.

As our key finding, migration involves sizeable positive returns for earnings and employment, both against staying and against job change in the East. Migrants are negatively selected with regard to previous earnings and employment in the East, experiencing a distinct premigration dip in outcomes. The returns to migration are the higher, the worse are earnings and employment in the East before migration. Our subsequent analysis shows that some of our findings differ from standard difference-in-differences estimates and that it is important to use data at a monthly frequency to account for the pre-migration dip in outcomes.

In light of the high returns to migration, it remains a puzzle as to why migration from East to West Germany in the 1990s was not even higher in the absence of common barriers to migration (legal restrictions, language/cultural differences). Our analysis points to the role of 
Table 4: Expectations and Worries

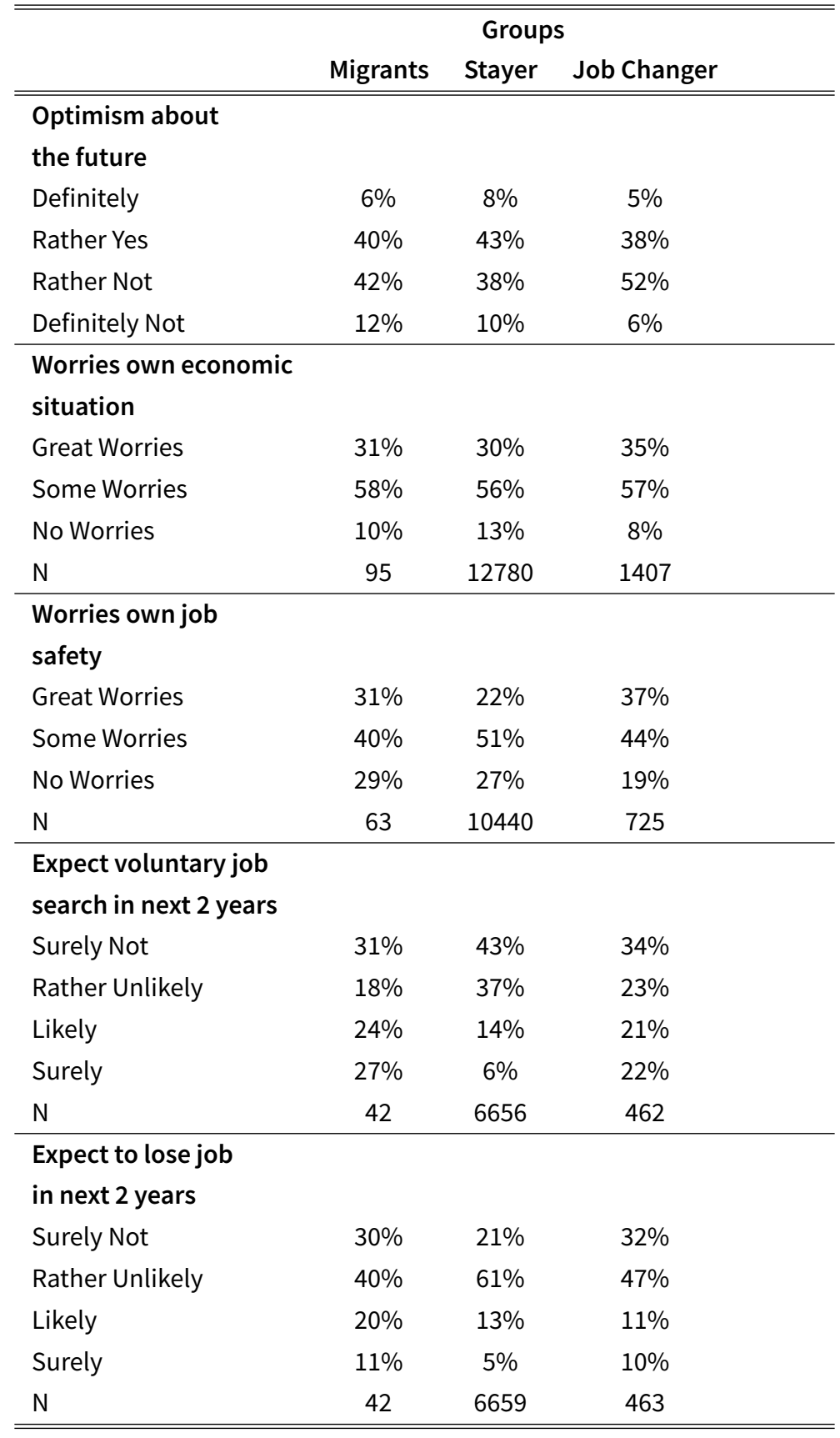

Notes: The displayed sample sizes refer to the number of individuals in the data that the values are based on. All results are weighted by population weights and the results for job changers and stayers are reweighted to reflect the distribution of control variables among migrants. Results refer to the year before migration/job change for migrants and job changers. For stayers, each year between 1993 and 2003 is counted.

Source: Own calculations based on SOEP v30. 
migration costs and expectations about future labor market prospects in the East. Because BASiD lacks information on these, we resort to evidence based on the SOEP, with the caveat in mind that the number of migrants recorded in the SOEP is much smaller than in BASiD. We find that future migrants have worse expectations, worry more about their current economic situation, and show lower behavioral barriers to mobility. We conclude that negative labor market prospects in East Germany were a key driver for the second wave of East-toWest migration. In turn, being employed in a stable job in East Germany strongly reduces the willingness to migrate, also because returns to migration are much lower for such workers. Still, a large number of East Germans with similarly bad labor market prospects in East Germany as the migrants choose not to migrate because of monetary and behavioral barriers to migration. 


\section{References}

Adda, Jérôme (2019): Regional Wage Disparities and Migration. In: Unpublished Manuscript.

Alm, Bastian; Engel, Dirk; Weyh, Antje (2014): Does Switching to a Western German Employer Still Pay Off? In: Jahrbücher für Nationalökonomie und Statistik, Vol. 234, No. 5, p. 546571.

Amior, Michael (2015): Why are higher skilled workers more mobile geographically? In: CEP Discussion Paper, Vol. dp1338.

Armstrong, Alex; Lewis, Frank D. (2012): International migration with capital constraints. In: The Canadian Journal of Economics, Vol. 45, No. 2, p. 732-754.

Arntz, Melanie; Gregory, Terry; Lehmer, Florian (2014): Can regional employment disparities explain the allocation of human capital across space? In: Regional Studies, Vol. 48, No. 10, p. $1719-1738$.

Bartolucci, Cristian; Villosio, Claudia; Wagner, Martin (2018): Who migrates and why? Evidence from Italian administrative data. In: Journal of Labor Economics, Vol. 36, No. 2, p. 551-588.

Biewen, Martin; Fitzenberger, Bernd; Osikominu, Aderonke; Paul, Marie (2014): The effectiveness of public-sponsored training revisited: The importance of data and methodological choices. In: Journal of Labor Economics, Vol. 32, No. 4, p. 837-897.

Borjas, George J. (1987): Self-Selection and the Earnings of Immigrants. In: The American Economic Review, Vol. 77, No. 4, p. 531 - 553.

Borjas, George J; Bronars, Stephen G; Trejo, Stephen J (1992): Self-selection and internal migration in the United States. In: Journal of Urban Economics, Vol. 32, No. 2, p. 159-185.

Bound, John; Holzer, Harry J. (2000): Demand shifts, population adjustments, and labor market outcomes during the 1980s. In: Journal of Labor Economics, Vol. 18, No. 1, p. 20-54.

Brücker, Herbert; Trübswetter, Parvati (2007): Do the best go West? An analysis of the selfselection of employed East-West migrants in Germany. In: Empirica, Vol. 34, No. 4, p. 371 $-395$.

Burda, Michael C. (1993): The determinants of East-West German migration - Some first results. In: European Economic Review, Vol. 37, No. 2-3, p. 452 - 461. 
Burda, Michael C.; Hunt, Jennifer (2001): From Reunification to Economic Integration: Productivity and the Labor market in Eastern Germany. In: Brookings Papers on Economic Activity, Vol. 32, No. 2, p. 1 - 92.

Burda, Michael Christopher (1995): Migration and the option value of waiting. In: The Economic and Social Review, Vol. 27, No. 1, p. 1-19.

Busso, Matias; DiNardo, John; McCrary, Justin (2014): New evidence on the finite sample properties of propensity score reweighting and matching estimators. In: Review of Economics and Statistics, Vol. 96, No. 5, p. 885-897.

Caliendo, Marco; Cobb-Clark, Deborah A.; Hennecke, Juliane; Uhlendorffd, Arne (2019): Locus of control and internal migration. In: Regional Science and Urban Economics, Vol. 79.

Caliendo, Marco; Künn, Steffen; Mahlstedt, Robert (2017): The return to labor market mobility. In: Journal of Public Economics, Vol. 148, p. 136-151.

Canache, Damarys; Hayes, Matthew; Mondak, Jeffery J; Wals, Sergio C (2013): Openness, extraversion and the intention to emigrate. In: Journal of Research in Personality, Vol. 47, No. 4, p. 351-355.

Chiquiar, Daniel; Hanson, Gordon H. (2005): International migration, self-selection, and the distribution of wages: Evidence from Mexico and the United States. In: Journal of Political Economy, Vol. 113, No. 2, p. 239 - 281.

De la Roca, Jorge (2017): Selection in initial and return migration: Evidence from moves across Spanish cities. In: Journal of Urban Economics, Vol. 100, p. 33-53.

De la Roca, Jorge; Puga, Diego (2017): Learning by working in big cities. In: The Review of Economic Studies, Vol. 84, No. 1, p. 106-142.

Dustmann, Christian; Glitz, Albrecht (2011): Migration and education. In: Handbook of the Economics of Education, North-Holland, p. 327-439.

Fackler, Daniel; Rippe, Lisa (2017): Losing work, moving away? Regional mobility after job loss. In: Labour, Vol. 31, No. 4, p. 457-479.

Fitzenberger, Bernd; Sommerfeld, Katrin; Steffes, Susanne (2013): Causal effects on employment after first birth - A dynamic treatment approach. In: Labour Economics, Vol. 25, p. 49-62.

Fuchs-Schündeln, Nicola; Krueger, Dirk; Sommer, Mathias (2010): Inequality trends for Germany in the last two decades: A tale of two countries. In: Review of Economic Dynamics, Vol. 13, No. 1, p. 103-132.

Fuchs-Schündeln, Nicola; Schündeln, Matthias (2009): Who stays, who goes, who returns? East-West Migration within Germany since reunification. In: Economics of Transition, Vol. 17, No. 4, p. $703-738$. 
Ham, John C.; Li, Xianghong; Reagan, Patricia B. (2011): Matching and semi-parametric IV estimation, a distance-based measure of migration, and the wages of young men. In: Journal of Econometrics, Vol. 161, No. 2, p. 208 - 227.

Heckman, James J (1979): Sample selection bias as a specification error. In: Econometrica, Vol. 47, No. 1, p. $153-161$.

Heckman, James J.; Navarro, Salvador (2007): Dynamic discrete choice and dynamic treatment effects. In: Journal of Econometrics, Vol. 136, No. 2, p. 341-396.

Heckman, James J; Smith, Jeffrey A (1999): The Pre-programme Earnings Dip and the Determinants of Participation in a Social Programme. Implications for Simple Programme Evaluation Strategies. In: The Economic Journal, Vol. 109, No. 457, p. 313-348.

Heise, Sebastian; Porzio, Thomas (2019): Spatial Wage Gaps and Frictional Labor Markets. In: CEPR Discussion Paper No. DP14197.

Herzog, Henry W.; Schlottmann, Alan M. (1993): Migration as Spatial Job-Search: A Survey of Empirical Findings. In: Regional Studies, Vol. 27, No. 4, p. 327- 340.

Herzog, Henry W.; Schlottmann, Alan M. (1984): Labor force mobility in the United States. In: International Regional Science Review, Vol. 9, No. 1, p. 43-58.

Herzog, Henry W.; Schlottmann, Alan M. (1982): Home economic conditions and the decision to migrate. In: Southern Economic Journal, Vol. 48, No. 4, p. 950-961.

Hochfellner, Daniela; Müller, Dana; Wurdack, Anja (2012): Biographical data of social insurance agencies in Germany. In: Schmollers Jahrbuch, Vol. 3, p. 443-451.

Huber, Martin; Lechner, Michael; Wunsch, Conny (2013): The performance of estimators based on the propensity score. In: Journal of Econometrics, Vol. 175, No. 1, p. 1-21.

Hunt, Gary L.; Mueller, Richard E. (2004): North American migration. In: The Review of Economics and Statistics, Vol. 86, No. 4, p. 988-1007.

Hunt, Jennifer (2006): Staunching Emigration from East Germany: Age and the Determinants of Migration. In: Journal of the European Economic Association, Vol. 4, No. 5, p. 1014 1037.

Hunt, Jennifer (2000): Why Do People Still Live in East Germany? In: Working Paper Series NBER, Vol. 7564.

Huttunen, Kristiina; Moen, Jarle; Salvanes, Kjell G. (2018): Job loss and regional mobility. In: Journal of Labor Economics, Vol. 36, No. 2, p. 479-509.

Imbens, Guido W. (2000): The role of the propensity score in estimating dose-response functions. In: Biometrika, Vol. 87, No. 3, p. 706-710. 
Jaeger, David A; Dohmen, Thomas; Falk, Armin; Huffman, David; Sunde, Uwe; Bonin, Holger (2010): Direct evidence on risk attitudes and migration. In: The Review of Economics and Statistics, Vol. 92, No. 3, p. 684-689.

Jurajda, Stepan; Harmgart, Heike (2007): When do female occupations pay more? In: Journal of Comparative Economics, Vol. 35, No. 1, p. 170-187.

Kaestner, Robert; Malamud, Ofer (2014): Self-selection and international migration: New evidence from Mexico. In: Review of Economics and Statistics, Vol. 96, No. 1, p. 78-91.

Kennan, John; Walker, James R. (2011): The effect of expected income on individual migration decisions. In: Econometrica, Vol. 79, No. 1, p. 211-251.

Krueger, Alan B.; Pischke, Jörn-Steffen (1995): A Comparative Analysis of East and West German Labor Markets: Before and After Unification. In: Freeman, Richard B.; Lawrence F. Katz, Editors (Eds.) Differences and Changes in Wage Structures, University of Chicago Press, p. $405-446$.

Lechner, Michael (2001): Econometric Evaluation of Labour Market Policies, Vol. 13, chap. Identification and estimation of causal effects of multiple treatments under the conditional independence assumption. ZEW Economic Studies, p. 43-58.

Lehmer, Florian; Ludsteck, Johannes (2011): The returns to job mobility and inter-regional migration: Evidence from Germany. In: Papers in Regional Science, Vol. 90, No. 3, p. 549571.

Liepmann, Hannah (2018): The impact of a negative labor demand shock on fertility - Evidence from the fall of the Berlin Wall. In: Labour Economics, Vol. 54, p. 210-224.

Lkhagvasuren, Damba (2014): Education, mobility and the college wage premium. In: European Economic Review, Vol. 67, p. 159-173.

McKenzie, David; Stillman, Steven; Gibson, John (2010): How important is selection? Experimental vs. non-experimental measures of the income gains from migration. In: Journal of the European Economic Association, Vol. 8, No. 4, p. 913-945.

Nakosteen, Robert A; Westerlund, Olle (2004): The effects of regional migration on gross income of labour in Sweden. In: Papers in Regional Science, Vol. 83, No. 3, p. 581-595.

Nakosteen, Robert A; Zimmer, Michael (1980): Migration and income: the question of selfselection. In: Southern Economic Journal, Vol. 46, No. 3, p. 840-851.

Orlowski, Robert; Riphahn, Regina T. (2009): The East German wage structure after transition. In: The Economics of Transition, Vol. 17, No. 4, p. 629-659.

Parey, Matthias; Ruhose, Jens; Waldinger, Fabian; Netz, Nicolai (2017): The selection of highskilled emigrants. In: Review of Economics and Statistics, Vol. 99, No. 5, p. 776-792. 
Pissarides, Christopher A.; Wadsworth, Jonathan (1989): Unemployment and the interregional mobility of labour. In: The Economic Journal, Vol. 397, p. 739-755.

Prantl, Susanne; Spitz-Oener, Alexandra (2019): The Impact of Immigration on Competing Natives' Wages: Evidence from German Reunification. In: Review of Economics and Statistics, Vol. 102, No. 1, p. $79-97$.

Roback, Jennifer (1982): Wages, rents, and the quality of life. In: Journal of Political Economy, Vol. 90, No. 6, p. 1257-1278.

Rosen, Sherwin (1972): Learning and experience in the labor market. In: Journal of Human Resources, Vol. 7, No. 3, p. 326-342.

Sianesi, Barbara (2004): An evaluation of the Swedish system of active labor market programs in the 1990s. In: The Review of Economics and Statistics, Vol. 86, No. 1, p. 133-155.

Smolny, W.; Kirbach, M. (2011): Wage differentials between East and West Germany: Are they related to the location or to the people? In: Applied Economics Letters, Vol. 18, No. 9, p. 873-879.

Snower, Dennis J.; Merkl, Christian (2006): The Caring Hand that Cripples: The East German Labor Market after Reunification. In: The American Economic Review, Vol. 96, No. 2, p. 375-382.

Tunali, Insan (2000): Rationality of migration. In: International Economic Review, Vol. 41, No. 4, p. 893-920.

Venhorst, Viktor A; Cörvers, Frank (2018): Entry into working life: Internal migration and the job match quality of higher-educated graduates. In: Journal of Regional Science, Vol. 58, No. 1 , p. 116-140.

Vortmann, Heinz; Goebel, Jan; Krause, Peter; Wagner, Gert G (2013): Zur Entwicklung der Preisniveaus in Ost-und Westdeutschland: Zugleich eine Dokumentation verschiedener Preisniveau-Zeitreihen für das geteilte und für das vereinigte Deutschland. In: DIW Discussion Papers 1269.

Wozniak, Abigail (2010): Are college graduates more responsive to distant labor market opportunities? In: Journal of Human Resources, Vol. 45, No. 4, p. 944-970.

Yankow, Jeffrey J (2003): Migration, job change, and wage growth: A new perspective on the pecuniary return to geographic mobility. In: Journal of Regional Science, Vol. 43, No. 3, p. 483-516.

Young, Alwyn (2013): Inequality, the urban-rural gap, and migration. In: The Quarterly Journal of Economics, Vol. 128, No. 4, p. 1727-1785.

Zaiceva, Anzelika (2010): East-West migration and gender: Is there a differential effect for migrant women? In: Labour Economics, Vol. 17, No. 2, p. 443-454. 
Zaiceva, Anzelika (2006): Self-Selection and the Returns to Geographic Mobility: What Can Be Learned from the German Reunification'Experiment'. In: IZA Discussion Paper No. 2524. 


\section{Appendix}

\section{A. Dynamic Model}

We posit a three period model with periods $t=0,1,2$. The employment state in period $t$ while remaining in the East is given by $e_{t}$, with $e_{t}=1$ employed or $e_{t}=0$ unemployed. We model East-to-West migration at the beginning of period $t=1\left(m_{1}=1\right)$ or period $t=2\left(m_{1}=0\right.$ and $m_{2}=1$ ). The model is dynamic such that not migrating in period 1 entails the possibility to migrate in period 2. No migration is the event $m_{1}=0$ and $m_{2}=0$. The changes in employment while remaining in the East are assumed to follow an exogenous Markov process. Moving to the West involves finding a job with a fixed wage. This means that the wage in the West (and also in the East, see below) is unaffected by individual employment shocks in the East, which is plausible since a negative labor demand shock for an individual in East Germany is unlikely to have a strong impact on labor market chances in West Germany. This assumption seems justified because the risk of job loss in East Germany is high due to the reunificationcaused transition process, implying that a job loss in East Germany is not viewed as a negative signal by West German employers. Also note that this is not inconsistent with a positive cross-sectional correlation between outcomes in the East and in the West because our theoretical model holds conditional upon observables and unobservables which jointly affect employment and wages. Further, the qualitative results of the model still hold as long as labor market prospects in West Germany are less negatively affected by job loss than labor market prospects in West Germany.

The basic structure of the model is visualized in Figure 13. We consider an individual who lives in the East in period 0 with given employment state in period $0, e_{0}$, forming the start point in Figure 13. Migration is an absorbing state involving moving to a job in the West with certain wage $w^{W}$. Having migrated in period $1\left(m_{1}=1\right.$, branch to the left in Figure 13), the individual receives the same wage $w^{W}$ until period 2 (no employment risk in the West). In contrast, there is a sizeable employment risk in the East. It is not certain that an unemployed (employed) worker finds a (keeps her) job in the East the next period (these are the branches in the middle and on the right of Figure 13 for $m_{1}=0$ and $\left.m_{2}=0\right)$. Conditional on being employed $\left(e_{t}=1\right)$, the wage in the East in period $t$ is $w^{E}$ and income is zero when unemployed $e_{t}=0$, i.e. the wage is the additional income when employed.

Define the Markov transition probability $p_{s, t}=P\left(e_{t}=1 \mid e_{t-1}=s, m_{t}=0\right)$ as the probability to be employed in the East in period $t=1,2$, given that the individual has employment state $s$ in 
Figure 13: Model Visualization

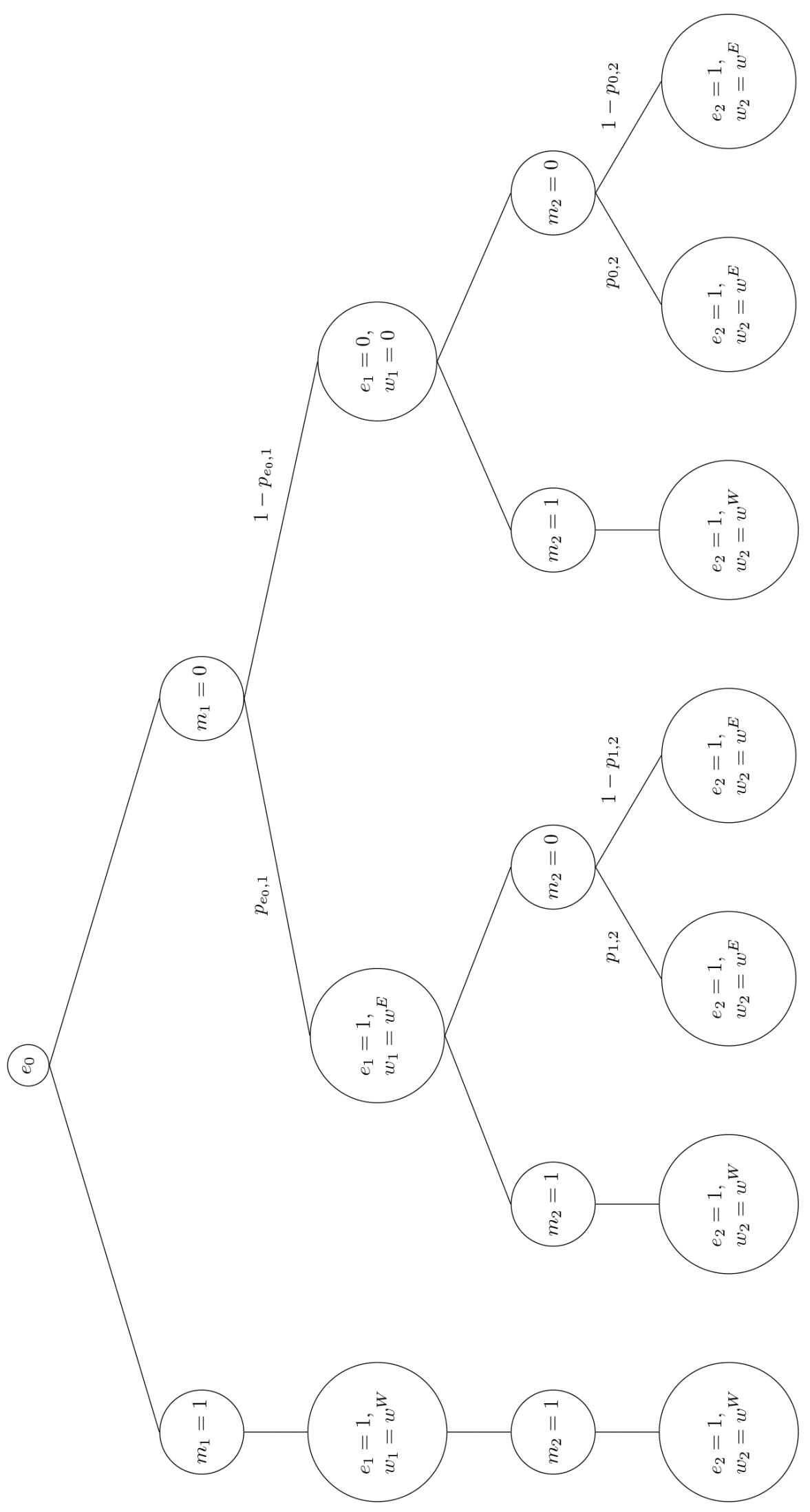

Notes: The graph describes individual wages, employment and migration state at each decision node of the model. 
the previous period $t-1$ and that the individual has not migrated up until period $t$ (branches in Figure 13 for $m_{1}=0$ and $m_{2}=0$ ). For example, $p_{0,1}$ is the probability that an unemployed individual in period 0 is employed in period 1 in the East given that the individual has not migrated up until period 1 . We assume state dependence in employment such that $p_{1, t}>p_{0, t}$, i.e. remaining employed is more likely than finding a job. Individuals form expectations in period $t-1$, given employment state $s$, about their employment probability in period $t, p_{s, t}^{e}$. As a behavioral bias, the subjective expectation $p_{s, t}^{e}$ may differ from the objective $p_{s, t}$.

Migration involves fixed individual costs $C_{t}$ in the period of migration $t=1,2$. $C_{t}$ is continuously distributed with positive expectation and full support over the real line. $F C_{t}$ is its distribution function and $f_{t}$ the density, conditional upon not having migrated by the end of period $t-1$. $C_{2}=C_{1}+\epsilon$, where $C_{1}$ and $\epsilon$ are independent random variables which are also independent of employment and wages, implying positively correlated costs $\left[\operatorname{Cov}\left(C_{1}, C_{2}\right)>0\right]$.

Total utility for the two time periods, $t=1,2$, is $V\left(e_{0}\right)=u_{1}\left(m_{1}, e_{1}\right)+u_{2}\left(m_{2}, e_{2}\right) . u_{t}$ is the period specific utility being linear in income and depending upon migration and employment state. Specifically, $u_{1}\left(m_{1}, e_{1}\right)=m_{1} \cdot\left(w^{W}-C_{1}\right)+\left(1-m_{1}\right) \cdot e_{1} \cdot w^{E}$, and $u_{2}\left(m_{1}, m_{2}, e_{2}\right)=$ $m_{1} w^{W}+\left(1-m_{1}\right)\left(m_{2}\left(w^{W}-C_{2}\right)+\left(1-m_{2}\right) \cdot e_{2} \cdot w^{E}\right)$. Individuals decide upon migration at the beginning of period $t$ based on the information in period $t-1$ without knowing the period $t$ employment state in the East. We solve the decision problem backwards. The migration decision in period 2 , conditional on not having migrated in period 1 , is based on maximizing

$\max _{\left\{m_{2}\right\}} E\left(u_{2}\left(0, m_{2}, e_{2}\right) \mid e_{1}\right)=m_{2} \cdot\left(w^{W}-C_{2}\right)+\left(1-m_{2}\right) \cdot p_{e_{1}, 2}^{e} \cdot w^{E}$,

where expectations are taken with respect to the subjective probability $p_{e_{1}, 2}^{e}$. Thus, the individual migrates, if $\left(w^{W}-C_{2}\right)>p_{e_{1}, 2}^{e} \cdot w^{E}$, i.e. $m_{2}^{*}\left(e_{1}\right)=1$ if $C_{2}<w^{W}-p_{e_{1}, 2}^{e} \cdot w^{E}$ and $m_{2}^{*}\left(e_{1}\right)=0$ if $C_{2} \geq w^{W}-p_{e_{1}, 2}^{e} \cdot w^{E}$. The maximized expected utility for period 2 given $e_{1}$ and $m_{1}=0$ is

$E\left(u_{2}\left(0, m_{2}^{*}\left(e_{1}\right), e_{2}\right) \mid e_{1}\right)=\max (\underbrace{w^{W}-C_{2}}_{m_{2}=1 \mid e_{1}}, \underbrace{e_{e_{1}, 2} \cdot w^{E}}_{m_{2}=1 \mid e_{1}})$.

The probability to migrate in period 2 given the information in period 1 is

$\widetilde{F C}_{2}\left(e_{1}, C_{1}\right) \equiv F C_{2}\left(w^{W}-p_{e_{1}, 2}^{e} \cdot w^{E}\right)$,

where $\widetilde{F C}_{2}\left(e_{1}, C_{1}\right)$ is the conditional distribution function of migration costs $C_{2}$ given $C_{1}$ among those not having migrated by the end of period 1 . This probability increases in $w^{W}$ and falls both in $w^{E}$ and in the probability to be employed in period 2 in the East. Unemployed individuals are more likely to migrate if employment expectations are lower for the unemployed than for the employed, i.e. $p_{0,2}^{e}<p_{1,2}^{e}$. This is likely to be the case given that $p_{0,2}<p_{1,2}$.

The cost thresholds $C_{2,0}=w^{W}-p_{0,2}^{e} \cdot w^{E}$ when unemployed in $\mathrm{t}=1$, and $C_{2,1}=w^{W}-p_{1,2}^{e} \cdot w^{E}$ when employed in $\mathrm{t}=1$, are the critical values. With migration costs below (above) these thresh- 
olds, the individual migrates (does not migrate) in period 2. Because of lower employment chances in the East, it holds that $C_{2,1}<C_{2,0}$ for the unemployed, who are therefore more likely to migrate.

The migration decision in period 1 involves the decision about migrating now versus staying with the option to migrate in period 2 . The individual maximizes

$$
\begin{aligned}
& \max _{\left\{m_{1}\right\}} E\left[m_{1} \cdot\left(\left(w^{W}-C_{1}\right)+w^{W}\right)+\left(1-m_{1}\right) \cdot\left(e_{1} w^{E}+E\left(u_{2}\left(0, m_{2}^{*}\left(e_{1}\right), e_{2}\right) \mid e_{1}, m_{1}=0\right) \mid e_{0}\right)\right] \\
& =m_{1} \cdot\left(2 w^{W}-C_{1}\right)+\left(1-m_{1}\right) \cdot\left\{p_{e_{0}, 1}^{e} w^{E}\right. \\
& +\left(1-p_{e_{0}, 1}^{e}\right)\left[\left(1-\widetilde{F C}_{2}\left(0, C_{1}\right)\right) p_{0,2}^{e} w^{E}+\widetilde{F C}_{2}\left(0, C_{1}\right)\left(w^{W}-E\left(C_{2} \mid C_{2}<C_{2,0}\right)\right)\right] \\
& \left.+p_{e_{0}, 1}^{e}\left[\left(1-\widetilde{F C_{2}}\left(1, C_{1}\right)\right) p_{1,2}^{e} w^{E}+\widetilde{F C_{2}}\left(1, C_{1}\right)\left(w^{W}-E\left(C_{2} \mid C_{2}<C_{2,1}\right)\right)\right]\right\} .
\end{aligned}
$$

The individual migrates in period 1, i.e. $m_{1}=1$ iff the utility difference between $2 w^{W}-C_{1}$ (wage income in periods 1 and 2 in the West minus migration costs) and the expected utility when remaining in the East in period 1

$$
\begin{aligned}
& \left\{p_{e_{0}, 1}^{e} w^{E}+\left(1-p_{e_{0}, 1}^{e}\right)\left[\left(1-\tilde{F C_{2}}\left(0, C_{1}\right)\right) p_{0,2}^{e} w^{E}+\tilde{F C_{2}}\left(0, C_{1}\right)\left(w^{W}-E\left(C_{2} \mid C_{2}>C_{2,0}\right)\right)\right]\right. \\
& \left.+p_{e_{0}, 1}^{e}\left[\left(1-\tilde{F C_{2}}\left(1, C_{1}\right)\right) p_{1,2}^{e} w^{E}+\tilde{F C_{2}}\left(1, C_{1}\right)\left(w^{W}-E\left(C_{2} \mid C_{2}>C_{2,1}\right)\right)\right]\right\}
\end{aligned}
$$

is positive. In the subsequent section, we show that the utility difference between migrating and not migrating in period 1 is a strictly negative function of $C_{1}$. For $C_{1}$ going to zero, the individual migrates and for $C_{1}$ going to infinity the individual does not migrate. Because the utility difference between migrating and not migrating falls in $C_{1}$, there will be a critical threshold $C_{1, e_{0}}$ depending upon the employment state in period 0 with (no) migration in period 1 if $C_{1}<(\geq) C_{1, e_{0}}$. The probability to migrate in period 1 is $F C_{1}\left(e_{0}\right)=P\left(C_{1}<C_{1, e_{0}}\right)$. Analogous to the migration decision in period 2 , the threshold - and therefore the migration probability - is higher for the non-employed than for the employed, i.e. $C_{1,1}<C_{1,0}$ and $F C_{1}(1)<F C_{1}(0)$.

There are further important insights to be gained. Since expectations about future employment matter, the period-1-migration probability falls with better employment prospects in the East irrespective of the employment situation in period 1. Analogously, if individuals expect period-2-wages in the East to rise, the expected utility of staying in the East increases and the migration probability falls. The option-value-of-waiting hypothesis of Burda (1993, 1995) relies on the anticipation of higher future wages in the East or on waiting for the uncertainty of migration outcomes in the West to resolve. In contrast, our model assumes that there is higher employment and income uncertainty in the East. Therefore, the key obstacles to migration are high migration costs and overly optimistic expectations about labor market chances in the East.

Now, we explain the link between the model and our subsequent empirical analysis estimating the dynamic returns to migration. In period 2, the migration problem is a purely static 
decision without consideration of the future. For all individuals migrating in period 2 and employment state $e_{1}$ in period 1 , the average return of migration with regard to earnings in period 2 is $\left(w^{W}-p_{e_{1}, 2} w^{E}\right)$. Analogously, the average period-1-income return to migration in period 1 is $\left(w^{W}-p_{e_{0}, 1} w^{E}\right)$ for individuals with employment state $e_{0}$ in period 0 .

The counterfactual of period-1-migration in period 2 involves staying in the East in period 1 with the possibility of migrating in period 2 . Thus, the average return in period 2 becomes

$$
\begin{aligned}
& w^{W}-p_{e_{0}, 1}(\underbrace{\tilde{F C_{2}}\left(1, C_{1}\right) w^{W}}_{m_{2}=1 \mid e_{1}=1}+\underbrace{\left.\left(1-\tilde{F C_{2}}\left(1, C_{1}\right)\right) p_{1,2} w^{e}\right)}_{m_{2}=0, e_{2}=1 \mid e_{1}=1} \\
& -\left(1-p_{e_{0}, 1}\right)(\underbrace{\tilde{F C_{2}\left(0, C_{1}\right) w^{W}}}_{m_{2}=1 \mid e_{1}=0}+\underbrace{\left.\left(1-\tilde{F C_{2}}\left(0, C_{1}\right)\right) p_{0,2} w^{e}\right)}_{m_{2}=0, e_{2}=1 \mid e_{1}=0} .
\end{aligned}
$$

The dynamic counterfactual in period 2 depends upon whether the individual is employed in period 1, i.e. $e_{1}=0,1$, migrates in period 2, i.e. $m_{2}=0,1$, and is employed in period 2, i.e. $e_{1}=0,1$, if not migrating.

Finally, a few further remarks on the role of migration costs are in order. Not migrating in period 1 and migrating in period 2 necessitates that $C_{2}$ is sufficiently low relative to $C_{1}$. If migration costs do not change, i.e. $C_{2}=C_{1}$, and individuals perfectly predict future employment probabilities, then migration in period 2 is low. Everybody with migration costs below $C_{2,1}$ has already migrated in period 1 . In fact, depending on the parameters of the decision problem, there may even be no migration in period 2 . The only migrants we would possibly observe in period 2 would be individuals who are employed in period 0 , who are not employed in period 1 , and for whom $C_{2,1}<C_{2}<C_{2,0}$. Migration in period 2 is higher, if random migration costs in period 2, $C_{2}$, are lower than $C_{1}$ for some of those not migrating in period 1 or if individuals overestimate future employment probabilities based on the information in period 0 or in period 1 . Thus, changing non-monetary migration costs or biased expectations provide behavioral explanations for delaying migration.

\section{A.1 Proof for the negative influence of $C_{1}$}

We need to show that the utility difference between migrating and not migrating in period 1 is a strictly negative function of $C_{1}$. To do so, we prove below that

$$
\frac{\partial\left[\left(1-\tilde{F C_{2}}\left(e_{1}, C_{1}\right)\right) p_{e_{1}, 2}^{e} w^{E}+\tilde{F C_{2}}\left(e_{1}, C_{1}\right)\left(w^{W}-E\left(C_{2} \mid C_{2}>C_{2, e_{1}}\right)\right)\right]}{\partial C_{1}}=-\tilde{F C_{2}}\left(e_{1}, C_{1}\right) .
$$

The right-hand-side of equation (9.1) lies strictly between -1 and 0 . Thus, the utility difference between migrating and not migrating in period 1 is a strictly negative function of $C_{1}$, because $\partial\left(2 w^{W}-C_{1}\right) / \partial C_{1}=-1$ and the derivative for the expected utility when staying in the East lies strictly between -1 and 0 . The latter follows because the derivatives of the two terms in 
brackets lie between -1 and 0 and the utility difference involves a convex combination of the two terms.

Proof of equation (9.1):

$$
\begin{aligned}
& \left(1-\tilde{F C_{2}}\left(e_{1}, C_{1}\right)\right) p_{e_{1}, 2}^{e} w^{E}+\tilde{F C_{2}}\left(e_{1}, C_{1}\right)\left(w^{W}-E\left(C_{2} \mid C_{2}>C_{2, e_{1}}\right)\right) \\
& =\int_{-\infty}^{C_{2, e_{1}}}\left(w^{W}-C_{2}\right) f\left(C_{2} \mid C_{1}\right) d C_{2}+\int_{C_{2, e_{1}}}^{\infty} p_{e_{1}, 2}^{e} w^{E} f\left(C_{2} \mid C_{1}\right) d C_{2} \\
& =\int_{-\infty}^{C_{2, e_{1}}}\left(w^{W}-C_{2}-p_{e_{1}, 2}^{e} w^{E}\right) f\left(C_{2} \mid C_{1}\right) d C_{2}+p_{e_{1}, 2}^{e} w^{E} \int_{-\infty}^{\infty} f\left(C_{2} \mid C_{1}\right) d C_{2} \\
& =\int_{-\infty}^{C_{2, e_{1}}}\left(C_{2, e_{1}}-C_{2}\right) f\left(C_{2} \mid C_{1}\right) d C_{2}+p_{e_{1}, 2}^{e} w^{E}
\end{aligned}
$$

because $C_{2, e_{1}}=w^{W}-p_{e_{1}, 2}^{e} w^{E}$. The second term in the sum does not depend upon $C_{1}$. The first term can be written as

$$
\begin{aligned}
& \int_{-\infty}^{C_{2, e_{1}}}\left(C_{2, e_{1}}-C_{2}\right) f\left(C_{2} \mid C_{1}\right) d C_{2} \\
& =\int_{-\infty}^{C_{2, e_{1}}-C_{1}}\left(C_{2, e_{1}}-C_{1}-\bar{C}\right) f_{0}(\bar{C}) d \bar{C},
\end{aligned}
$$

where we substitute $\bar{C}=C_{2}-C_{1}$ and use the fact that $f_{0}(\bar{C})$ is the pdf of $\epsilon$ which does not depend upon $C_{1}$. Rewrite this expression as

$$
\begin{aligned}
& \left(C_{2, e_{1}}-C_{1}\right) \int_{-\infty}^{C_{2, e_{1}}-C_{1}} f_{0}(\bar{C}) d \bar{C}-\int_{-\infty}^{C_{2, e_{1}}-C_{1}} \bar{C} f_{0}(\bar{C}) d \bar{C} \\
& =\left(C_{2, e_{1}}-C_{1}\right) \tilde{F C_{2}}\left(e_{1}, C_{1}\right)-\int_{-\infty}^{C_{2, e_{1}}-C_{1}} \bar{C} f_{0}(\bar{C}) d \bar{C}
\end{aligned}
$$

Note that $f_{0}(\bar{C})$ is the density of the distribution function $F_{0}(\bar{C})$. Further, it holds that $\tilde{F C_{2}}\left(e_{1}, C_{1}\right)=F_{0}\left(C_{2, e_{1}}-C_{1}\right)$. Now consider the first derivative with respect to $C_{1}$ (using Leibniz rule for the second term)

$$
\begin{aligned}
& \frac{\partial\left[\left(C_{2, e_{1}}-C_{1}\right) \tilde{F C} C_{2}\left(e_{1}, C_{1}\right)-\int_{-\infty}^{C_{2, e_{1}}-C_{1}} \bar{C} f_{0}(\bar{C}) d \bar{C}\right]}{\partial C_{1}} \\
& =-\tilde{F C_{2}}\left(e_{1}, C_{1}\right)-\left(C_{2, e_{1}}-C_{1}\right) f_{0}\left(C_{2, e_{1}}-C_{1}\right)+\left(C_{2, e_{1}}-C_{1}\right) f_{0}\left(C_{2, e_{1}}-C_{1}\right)=-\tilde{F C_{2}}\left(e_{1}, C_{1}\right)
\end{aligned}
$$

which completes the proof. 


\section{B. Temporal Alignment and Inverse Probability Reweighting}

\section{Job changers}

We start with the migration-vs-job-change treatment to describe the temporal alignment and reweighting, which is particularly important because of the strong pre-migration dip in earnings and employment shortly before migration/job change. We need to balance on the one hand calendar time to ensure comparability in economic conditions and on the other hand time until treatment because of the dip before treatment. Since the pre-treatment dip involves a large change during a few months and we allow for calendar time controls, we align exactly based on the number of months until/since migration and we contrast migrants and job changers treated in the same calendar year. This means that the individual observations used to compute the monthly averages by time relative to treatment stem from different calendar months. We estimate returns to migration for earnings and employment, i.e. monthly means of daily earnings and employment rates are compared across the different groups. Figure 14 illustrates the approach for an example.

Figure 14: Migration Cohort 1994 - Pre-migration Temporal Alignment

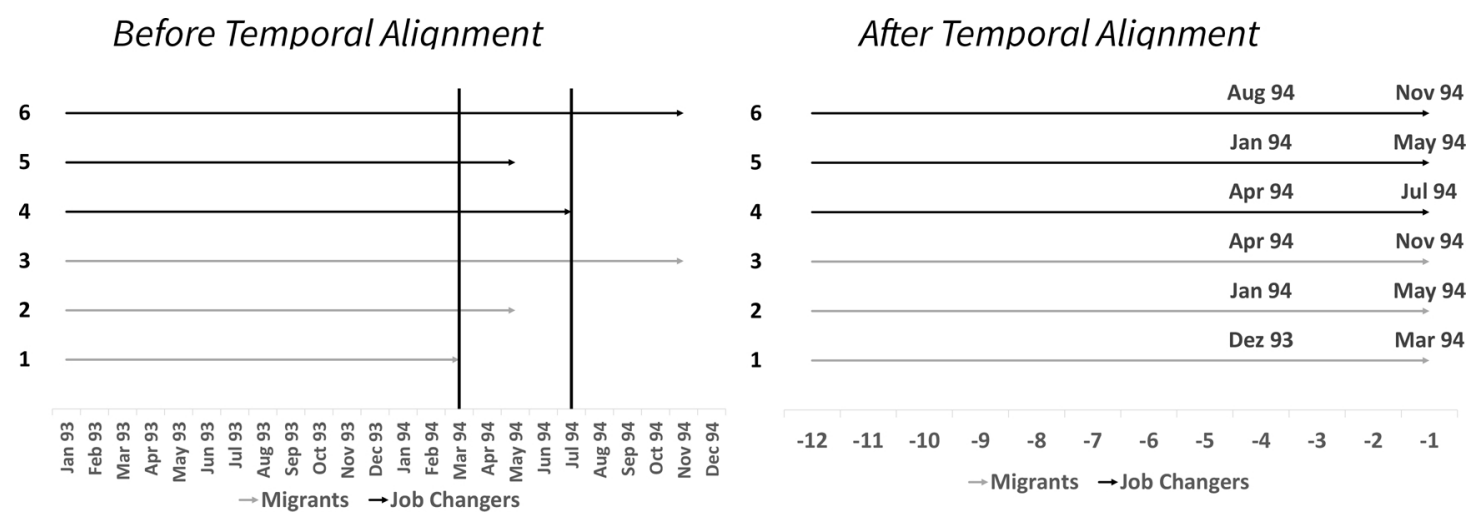

Notes: The figure demonstrates the implementation of temporal alignment for migrants and job changes in the same calendar year based on the number of months until/since migration.

For six individuals in the 1994 migration cohort, the graph to the left shows the timing of migration and job change, respectively. Individuals 1 to 3 are migrants and their pre-migration spells are completed in the month before migration (when the line ends). Correspondingly, the lines for the job changers 4 to 6 end in the month before job change. Temporal alignment by calendar month (vertical lines) would imply that migrants and job changers would be compared at different points durations until treatment. In contrast, we align by duration until treatment, which allows us to trace the pre-treatment dip in earnings and employment, as shown in the graph to the right. Using the alignment in the graph to the right, we then estimate the average effect of treatment for the treated $A T T^{J C}(a)$ of migration-vs-job-change by contrasting the mean outcomes - after inverse probability reweighting to control for differences in observables - for each month $a$, i.e. separately for $a=-24, \ldots, 24$ before/after the date of migration/job change. 
Figure 15: $A T T^{J C}(-1)$ and $A T T^{J C}(-2)$ for Migration Cohort 1994
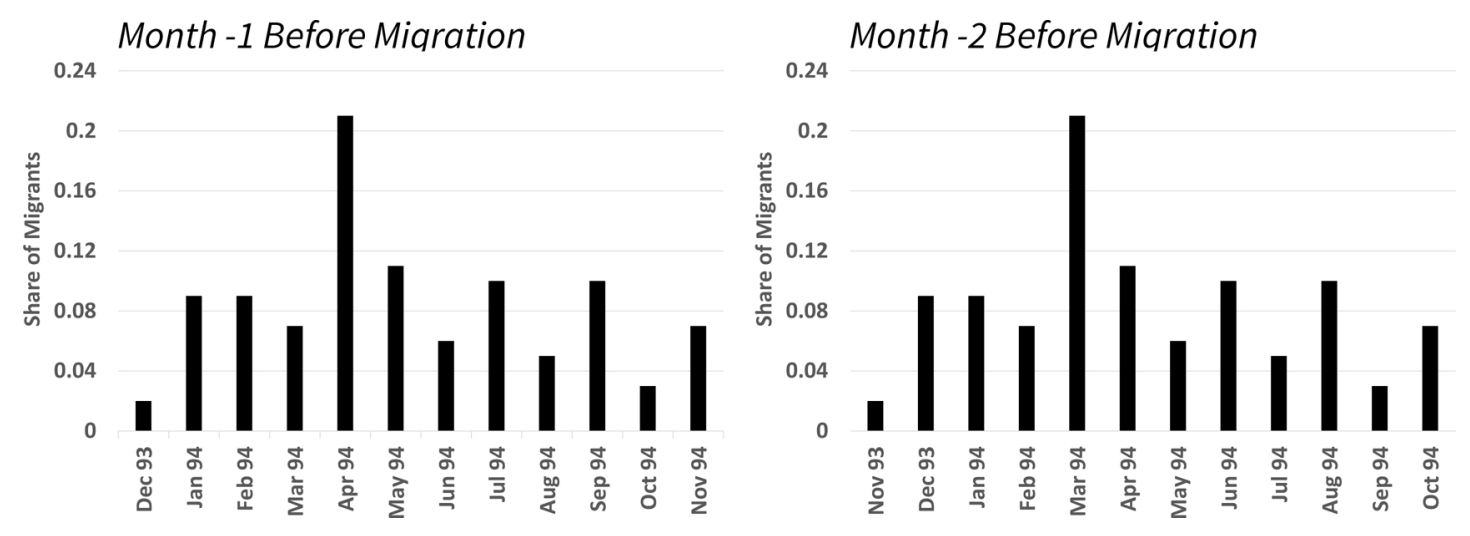

Notes: The figures show the shares of migrants used in the calculation of the weighted average of the ATT one month (left) and two months (right) before migration based on the 1994 migration cohort. Source: Own calculations based on BASiD 5109.

To take account of changes in the differences between migrants and job changers based on calendar time, each $A T T^{J C}(a)$ is a weighted average of yearly ATT's based on the migration cohorts by calendar years. This means that $A T T^{J C}(a)$ is estimated separately for each migration cohort from 1994 to 2004. Furthermore, the migration cohort specific $A T T^{J C}(a)$ is itself a weighted average of the $A T T^{J C}(a)$ by calendar month of migration. For migrants in a specific calendar month, the comparison for month $a$ relative to treatment includes job changers also $a$ month before/after job change in the same calendar month. To obtain the migration cohort specific $A T T^{J C}(a)$, we calculate a weighted average of the calendar month specific ATTs, using the share of migrants in this specific month relative to the total amount of migrants in this cohort. Figure 15 visualizes this approach for the $A T T^{J C}(-1)$ and $A T T^{J C}(-2)$ based on the 1994 migrant cohort.

The graph to the left shows the relevant 12-months window for the computation of $A T T^{J C, c}(a)$ for $a=-1$ ( $c=1994$ represents the migration cohort 1994), one month before migration, and the distribution of migrants across the 12-months window. The graph to the right considers the same for $a=-2$. For each calendar month, a separate $A T T_{m}^{J C, c}(a)$ is computed and then weighted by the share of migrants in this month relative to all migrants in migration cohort 1994. Thus, the overall $A T T^{J C}(a)$ can be formally expressed as

$A T T^{J C}(a)=\sum_{c=1994}^{2004} k_{c}\left(\sum_{m=1}^{12} s_{m}^{c} A T T_{m}^{J C, c}(a)\right)$,

where $k_{c}$ is the share of migrants in cohort c relative to the overall number of migrants, and $s_{m}^{c}$ is the share of migrants from cohort $\mathrm{c}$ in month $\mathrm{m}$ of the moving 12-months window relative to all migrants from cohort $\mathrm{c}$ in this 12 -months window.

In addition to temporal alignment, inverse probability reweighting (IPW) is used to balance the observable characteristics between job changers and migrants. Since we estimate the av- 
erage treatment effect on the treated, migrants get a weight of 1 and we reweight job changers such that the distribution of observable characteristics mimics the one among migrants. To obtain the weights for job changers, we estimate a logit model with the migration dummy as dependent variable and the covariates as observed one month before migration or job change as control variables. The estimated propensity scores, $\hat{p}\left(X_{i}\right)$, are used to compute the normalized weights for the control group using the following formula

$\widehat{w}_{j, m}^{c}=\frac{\frac{\hat{p}\left(X_{j}\right)}{1-\hat{p}\left(X_{j}\right)}}{\sum_{i \in N_{a}}\left(1-T_{i}\right) \frac{\hat{p}\left(X_{i}\right)}{1-\hat{p}\left(X_{i}\right)}}$

where $T_{i}$ is an indicator which is equal to $1(0)$ if individual $i$ is a migrant (a job changer) and $N_{a}$ are all individuals observed $a$ periods before/after migration/job change. Individuals with too large weights are discarded from the computation of the ATT, based on the method described in Huber/Lechner/Wunsch (2013). The $A T T_{m}^{J C, c}$ can then be expressed as $\frac{1}{\sum_{i \in N_{a}} T_{i}} \sum_{i \in M_{m}^{c}(a)} y_{i}-\sum_{j \in J C_{m}^{c}(a)} \hat{w}_{j, m}^{c} \cdot y_{j}$, where $M_{m}^{c}(a)$ are all migrants in cohort $c$ in month $m$ observed $a$ months before/since migration, $J C_{m}^{c}(a)$ is defined analogously for job changers, and $y_{i / j}$ is the outcome considered (earnings, employment).

\section{Stayers}

The temporal alignment and reweighting procedure is more complex for ATT ${ }^{\text {Stay }}$. Stayers do not experience a specific event (like a job change) in a specific year and, on average, stayers do not show the typical pre-treatment dip as migrants or job changers do. Thus, for a stayer, every individual observation from the relevant period of 12 months could be used as the counterfactual for the outcome of migrants one month before treatment. Therefore, when determining the mean earnings of stayers for say month - 1 of the 1994 migration cohort, we use all twelve observations from December 1993 to November 1994. We also do this for the estimation of IPW weights. For migrants, only one individual observation is used, namely the one from the month -1 . The 12 individual observations of a stayer will get different weights if the control variables for a stayer changes over the course of the 12 months. Table 5 shows the shift of weights for an individual stayer for the relevant 12 months of the migration cohort in 1994 for months -1 and -2 prior to migration. Our method is equivalent to replicating each stayer 12 times for the 12 potential "treatment" months (for which $a$ is set to 0 ) January to December 1994.

To determine mean earnings of stayers, the same method as for job changers is employed to align the distribution of stayers with that of migrants. For job changers, indicators for calendar month are used as control variables in the logistic regression in order to achieve temporal alignment. The only difference is that for each monthly average, observations from all stayers are used (instead of only the observations for job changers for whom the calendar month corresponds to the specific month before/after job change for which the mean earnings are computed). 
Table 5: Weight-Shifting for Stayers

\begin{tabular}{ccccc}
\hline \hline & \multicolumn{3}{c}{ Cohorts } & \\
Month & Year & Weights for Month -1 & Weights for Month -2 & Earnings \\
\hline \hline October & 1993 & $\cdot$ & $\cdot$ & 1250 \\
November & 1993 & $\cdot$ & 0.02 & 1250 \\
December & 1993 & 0.02 & 0.04 & 1250 \\
January & 1994 & 0.04 & 0.01 & 1250 \\
February & 1994 & 0.01 & 0.11 & 1250 \\
March & 1994 & 0.11 & 0.04 & 1370 \\
April & 1994 & 0.04 & 0.03 & 1370 \\
May & 1994 & 0.03 & 0.07 & 1370 \\
June & 1994 & 0.07 & 0.08 & 1370 \\
July & 1994 & 0.08 & 0.07 & 1410 \\
August & 1994 & 0.07 & 0.07 & 1410 \\
September & 1994 & 0.07 & 0.09 & 1410 \\
October & 1994 & 0.09 & 0.04 & 1410 \\
November & 1994 & 0.04 & $\cdot$ & 1410 \\
December & 1994 &. &. & 1410 \\
\hline \hline
\end{tabular}

Notes: The table displays the weighting scheme for an individual stayer which is used as part of the control group for migration cohort 1994. Weights are determined based on logistic regression with an migration/stayer indicator as dependent variable. Since every month between Jan and December could be a potential treatment month, all month between December 1993 - November 1994 can be used as control observations for the month before migration for migrants. This is represented in column "Weights for Month -1". It follows that all month between November 1993 and October 1994 can be used as control observations for month -2. Since weights are held constant for each potential treatment month, weights are shifted one month back as show in column "Weights for Month -2". Earnings are displayed to illustrate that the different monthly weights matter, if the earnings of a stayer change during the moving 12-months window.

Source: Own calculations based on BASiD 5109. 
C. Tables 
Table 6: Logit Models of Migration Determinants

\begin{tabular}{|c|c|c|}
\hline Reference Group & Job Changers & Stayer \\
\hline Female & $-0.506^{\star \star \star}$ & $-0.6533^{\star \star \star}$ \\
\hline Age & 0.0348 & $0.1412^{\star \star \star}$ \\
\hline $\operatorname{Age}^{2}$ & $-0.0007^{\star \star}$ & $-0.0022^{\star \star \star}$ \\
\hline Months in unemployment last 12 months & 0.0017 & 0.0172 \\
\hline Months in continuous unemployment & 0.0012 & $-0.0086^{\star}$ \\
\hline Number of job changes since 1992 & -0.0953 & $1.0697^{\star \star \star}$ \\
\hline Share in unemployment since 1990 & -0.011 & 0.0313 \\
\hline Earnings & 0.0025 & $-0.0064^{\star \star}$ \\
\hline Unemployment & $0.389^{\star \star}$ & $1.1969^{\star \star \star}$ \\
\hline Population in county of last job & -0.09 & -0.1255 \\
\hline Employment rate in county of last job & 0.0007 & 0.0019 \\
\hline Mean earnings potential in county of last job & $0.0238^{\star \star \star}$ & $0.0276^{\star \star \star}$ \\
\hline Tenure in current firm (unemployed $=0$ ) & 0.0007 & $-0.0109^{\star \star \star}$ \\
\hline Tenure in Industry of last Job & 0.0013 & -0.0002 \\
\hline Distance to Western border of county of last job & $-0.0023^{\star \star \star}$ & $-0.0021^{\star \star \star}$ \\
\hline Number of Employees in last firm & $-0.0293^{\star}$ & $-0.0713^{\star \star \star}$ \\
\hline Median Earnings in last firm & $0.004^{\star \star}$ & 0.0016 \\
\hline \multicolumn{3}{|l|}{ Education } \\
\hline High-School & -0.0526 & -0.1449 \\
\hline University & -0.0567 & -0.0792 \\
\hline Apprenticeship & (.) & (.) \\
\hline \multicolumn{3}{|l|}{ Industry in Last Job } \\
\hline Agriculture, Energy and Mining & -0.1522 & -0.0133 \\
\hline Manufacturing & 0.3138 & 0.3531 \\
\hline Trade, Transport and Communication & 0.0917 & 0.221 \\
\hline Services & 0.0829 & 0.2976 \\
\hline Banking and Insurance & -0.0115 & 0.2965 \\
\hline Non-commercial Enterprises, Civil Servants & 0.1572 & 0.3337 \\
\hline Construction & (.) & (.) \\
\hline \multicolumn{3}{|l|}{ Federal State of Last Job } \\
\hline Berlin & $-0.6502^{\star}$ & -0.3294 \\
\hline Brandenburg & 0.1678 & 0.1819 \\
\hline Mecklenburg-Vorpommern & -0.0159 & 0.007 \\
\hline Saxony & -0.1305 & -0.1111 \\
\hline Saxony-Anhalt & -0.0151 & 0.02 \\
\hline Thuringia & (.) & (.) \\
\hline \multicolumn{3}{|l|}{ Occupation in Last Job } \\
\hline Resource Extraction and Production & 0.2474 & $0.3975^{\star \star}$ \\
\hline Construction, Architecture & $0.4021^{\star \star}$ & $0.6095^{\star \star \star}$ \\
\hline Science, Media, Art, Culture & 0.3769 & 0.3563 \\
\hline Traffic, Logistics, Security & $0.4462^{\star \star}$ & $0.5863^{\star \star \star}$ \\
\hline Sales & $0.5105^{\star \star \star}$ & $0.6501^{\star \star \star}$ \\
\hline Management, Accounting, Law, Administration & 0.2126 & 0.2559 \\
\hline Health, Social, Education & 0.2302 & 0.185 \\
\hline Unskilled Worker & 0.0098 & 0.126 \\
\hline Agriculture & (.) & (.) \\
\hline \multicolumn{3}{|l|}{ Job Type } \\
\hline Craftsman & -0.0005 & 0.0502 \\
\hline Employee & 0.1528 & 0.1664 \\
\hline Part-Time & -0.0199 & 0.0292 \\
\hline In Apprenticeship & (.) & (.) \\
\hline Observations & 53848 & 3422762 \\
\hline
\end{tabular}

Notes: Results are coefficients from a logistic regression on an indicator for migration or job changing/staying. Observations for migrants compared to job changers are from the month before migration/job change and from all sample years. Observations for migrants compared to stayers come from the month before migration, for stayers all observations from all sample cohorts are used. These are thus aggregate results over all migration cohorts, in contrast to results used for the estimation of IPW where separate logistic regressions are estimate for each migration cohort. Additional controls used in the estimation of IPW but not displayed here to increase readability: dummies for the calendar month and retrospective values for the months 6, 12 and 24 before migration for the some of the labor market indicators. The logistic regression uses population weights. The Significance Levels are as follows: $1 \%$ $\star \star \star, 5 \%$ **, $10 \%$ *

Source: Own calculations based on BASiD 5109 
Table 7: Means of Control Variables before and after IPW (BASiD)

\begin{tabular}{|c|c|c|c|c|c|}
\hline & \multirow[b]{3}{*}{ Migrants } & \multicolumn{3}{|c|}{ Groups } & \\
\hline & & \multicolumn{2}{|c|}{ Stayer } & \multicolumn{2}{|c|}{ Job Changer } \\
\hline & & No IPW & IPW & No IPW & IPW \\
\hline Female (\%) & 35.52 & 55.38 & 35.22 & 49.95 & 35.19 \\
\hline Age & 39.33 & 42.11 & 39.46 & 40.81 & 39.46 \\
\hline $\mathrm{Age}^{2}$ & 1617.76 & 1855.39 & 1627.7 & 1743.86 & 1627.46 \\
\hline Tenure in Industry of last Job & 47.44 & 61.37 & 47.68 & 44.17 & 47.43 \\
\hline Tenure in current firm (unemployed $=0$ ) & 17.42 & 43.29 & 17.33 & 18.12 & 17.16 \\
\hline Months in unemployment last 12 months & 4.36 & 2.12 & 4.42 & 4.27 & 4.45 \\
\hline Months in continuous unemployment & 7.48 & 3.95 & 7.62 & 6.41 & 7.58 \\
\hline Number of job changes since 1992 & 2.36 & 1.62 & 2.4 & 2.23 & 2.39 \\
\hline Share in unemployment since 1990 & 20.77 & 14.34 & 20.67 & 21.16 & 20.66 \\
\hline Earnings & 30.43 & 52.86 & 30.44 & 32.63 & 30.14 \\
\hline Unemployment & 52.29 & 19.77 & 52.53 & 46.23 & 52.85 \\
\hline \multicolumn{6}{|l|}{ Characteristics of County of Last Job } \\
\hline Population in county of last job & 12.23 & 12.36 & 12.22 & 12.39 & 12.22 \\
\hline Employment rate in county of last job & 61.77 & 61.64 & 61.53 & 62.42 & 61.59 \\
\hline Mean earnings potential in county of last job & 56.72 & 56.68 & 56.91 & 55.97 & 56.85 \\
\hline Distance to Western border of county of last job & 106.62 & 111.34 & 107.04 & 113.38 & 107.12 \\
\hline \multicolumn{6}{|l|}{ Characteristics of Last Firm } \\
\hline Number of Employees in last firm & 3.7 & 4.29 & 3.69 & 4.03 & 3.7 \\
\hline Median Earnings in last firm & 55.13 & 60.24 & 55.36 & 54.65 & 55.31 \\
\hline \multicolumn{6}{|l|}{ Education (\%) } \\
\hline High School & 3 & 3.52 & 3.06 & 3.47 & 3.06 \\
\hline Apprenticeship & 84.58 & 81.94 & 84.65 & 84.75 & 84.57 \\
\hline University & 12.42 & 14.54 & 12.29 & 11.78 & 12.36 \\
\hline \multicolumn{6}{|l|}{ Federal State of Last Job (\%) } \\
\hline Berlin & 3.37 & 5.95 & 3.44 & 7.31 & 3.46 \\
\hline Brandenburg & 18.01 & 15.25 & 18.58 & 15.45 & 18.73 \\
\hline Mecklenburg-Vorpommern & 13.17 & 11.91 & 13.4 & 12.04 & 13.31 \\
\hline Saxony & 27.68 & 33.56 & 27.12 & 31.33 & 27.05 \\
\hline Saxony-Anhalt & 21.11 & 18.91 & 20.91 & 20.11 & 20.74 \\
\hline Thuringia & 16.66 & 14.42 & 16.55 & 13.75 & 16.7 \\
\hline \multicolumn{6}{|l|}{ Industry in Last Job (\%) } \\
\hline Agriculture, Energy and Mining & 3.92 & 4.39 & 3.94 & 4.86 & 3.92 \\
\hline Manufacturing & 15.21 & 15.76 & 14.94 & 13 & 15.21 \\
\hline Construction & 22.45 & 12.47 & 22.54 & 16.66 & 22.52 \\
\hline Trade, Transport and Communication & 13.12 & 11.63 & 13.05 & 12.11 & 12.81 \\
\hline Services & 29.58 & 34.19 & 29.89 & 31.58 & 30.07 \\
\hline Banking and Insurance & 10.09 & 7.37 & 10.08 & 10.04 & 9.94 \\
\hline Non-commercial Enterprises, Civil Servants & 5.62 & 14.2 & 5.56 & 11.75 & 5.54 \\
\hline \multicolumn{6}{|l|}{ Occupation in Last Job (\%) } \\
\hline Agriculture & 2.71 & 3.37 & 2.8 & 4.28 & 2.78 \\
\hline Resource Extraction and Production & 20.41 & 19.38 & 20.09 & 18.96 & 20.01 \\
\hline Construction, Architecture & 20.81 & 9.91 & 21.05 & 14.55 & 20.94 \\
\hline Science, Media, Art, Culture & 2.41 & 2.54 & 2.31 & 2.08 & 2.56 \\
\hline Traffic, Logistics, Security & 16.66 & 12.63 & 16.66 & 15.53 & 16.46 \\
\hline Sales & 10.42 & 8.49 & 10.19 & 9.1 & 10.16 \\
\hline Management, Accounting, Law, Administration & 14.85 & 22.89 & 14.81 & 18.94 & 14.91 \\
\hline Health, Social, Education & 8.48 & 17.66 & 8.74 & 11.86 & 8.76 \\
\hline Unskilled Worker & 3.24 & 3.13 & 3.34 & 4.69 & 3.41 \\
\hline \multicolumn{6}{|l|}{ Job Type(\%) } \\
\hline In Apprenticeship & 14.49 & 10.84 & 14.27 & 14.44 & 14.25 \\
\hline Craftsman & 38.46 & 28.91 & 38.51 & 32.28 & 38.53 \\
\hline Employee & 34.05 & 43.2 & 34.27 & 34.98 & 34.45 \\
\hline Part-Time & 13.01 & 17.06 & 12.95 & 18.3 & 12.77 \\
\hline
\end{tabular}

Notes: Descriptive Statistics for the variables, except for the earnings measures, are computed here as an average over all different calendar month, unlike in the estimation of returns. Observations for migrants and the "No IPW" category are weighted by population weights. For the "IPW" category, IPW are additionally used. For the earnings measure, first averaging over returns in a calendar month and then over all of the month in the year (weighted by the distribution of migrants across the year) and then aggregation over all years is used as described in the text.

Source: Own calculations based on BASID 5109. 
Table 8: Means of Moving Costs and Behavioral Variables before and after IPW - SOEP

\begin{tabular}{|c|c|c|c|c|c|}
\hline & \multirow[b]{2}{*}{ Migrants } & \multicolumn{2}{|c|}{ No IPW } & \multicolumn{2}{|c|}{ IPW } \\
\hline & & Stayer & $\mathrm{JC}$ & Stayer & $\mathrm{JC}$ \\
\hline Married & $44 \%$ & $71 \%$ & $65 \%$ & $62 \%$ & $68 \%$ \\
\hline Number of Children & 0.71 & 0.75 & 0.85 & 0.98 & 0.97 \\
\hline Own Property & $21 \%$ & $39 \%$ & $37 \%$ & $29 \%$ & $36 \%$ \\
\hline \multicolumn{6}{|l|}{ who moved to the West } \\
\hline Risk Aversion & 5.12 & 4.59 & 4.79 & 4.87 & 5.04 \\
\hline \multicolumn{6}{|l|}{ Attachment to } \\
\hline \multicolumn{6}{|l|}{ Place of Living } \\
\hline Very Strong & $25 \%$ & $31 \%$ & $31 \%$ & $31 \%$ & $22 \%$ \\
\hline Strong & $50 \%$ & $52 \%$ & $51 \%$ & $44 \%$ & $61 \%$ \\
\hline Weak & $23 \%$ & $16 \%$ & $16 \%$ & $21 \%$ & $15 \%$ \\
\hline None & $2 \%$ & $2 \%$ & $2 \%$ & $4 \%$ & $2 \%$ \\
\hline \multicolumn{6}{|l|}{$\begin{array}{l}\text { Conceivable to move away } \\
\text { (job- or family-related) }\end{array}$} \\
\hline Yes & $53 \%$ & $16 \%$ & $16 \%$ & $25 \%$ & $19 \%$ \\
\hline Depends & $31 \%$ & $35 \%$ & $38 \%$ & $36 \%$ & $44 \%$ \\
\hline No & $15 \%$ & $49 \%$ & $46 \%$ & $39 \%$ & $37 \%$ \\
\hline \multicolumn{5}{|l|}{ Conceivable to move } & to the West \\
\hline Yes, gladly & $10 \%$ & $3 \%$ & $4 \%$ & $6 \%$ & $3 \%$ \\
\hline Under some circumstances & $77 \%$ & $59 \%$ & $57 \%$ & $57 \%$ & $59 \%$ \\
\hline Rather not & $8 \%$ & $29 \%$ & $32 \%$ & $29 \%$ & $27 \%$ \\
\hline Definitely not & $5 \%$ & $8 \%$ & $8 \%$ & $8 \%$ & $11 \%$ \\
\hline
\end{tabular}

Notes: The displayed sample sizes refer to the number of individuals in the data that the values are based on. Results with "No IPW" are weighted by population weights and the results for job changers and stayers "With IPW" are additionally reweighted to reflect the distribution of control variables among migrants using IPW. Results refer to the year before migration/job change for migrants and job changers. For stayers, each year between 1993 and 2003 is counted. For risk aversion, the higher the number, the less risk-averse the individual.

Source: Own calculations based on SOEP v30. 
Table 9: Means of Expectations and Worries before and after IPW - SOEP

\begin{tabular}{|c|c|c|c|c|c|}
\hline & \multirow[b]{2}{*}{ Migrants } & \multicolumn{2}{|c|}{ No IPW } & \multicolumn{2}{|c|}{ IPW } \\
\hline & & Stayer & $\mathrm{JC}$ & Stayer & $\mathrm{JC}$ \\
\hline \multirow{2}{*}{\multicolumn{6}{|c|}{$\begin{array}{l}\text { Optimism about } \\
\text { the future }\end{array}$}} \\
\hline & & & & & \\
\hline Definitely & $6 \%$ & $8 \%$ & $6 \%$ & $8 \%$ & $5 \%$ \\
\hline Rather Yes & $40 \%$ & $46 \%$ & $43 \%$ & $43 \%$ & $38 \%$ \\
\hline Rather Not & $42 \%$ & $38 \%$ & $40 \%$ & $38 \%$ & $52 \%$ \\
\hline Definitely Not & $12 \%$ & $8 \%$ & $11 \%$ & $10 \%$ & $6 \%$ \\
\hline \multirow{2}{*}{\multicolumn{6}{|c|}{$\begin{array}{l}\text { Worries own economic } \\
\text { situation }\end{array}$}} \\
\hline & & & & & \\
\hline Great Worries & $31 \%$ & $28 \%$ & $44 \%$ & $30 \%$ & $35 \%$ \\
\hline Some Worries & $58 \%$ & $60 \%$ & $50 \%$ & $56 \%$ & $57 \%$ \\
\hline No Worries & $10 \%$ & $13 \%$ & $6 \%$ & $13 \%$ & $8 \%$ \\
\hline \multirow{2}{*}{\multicolumn{6}{|c|}{$\begin{array}{l}\text { Worries own job } \\
\text { safety }\end{array}$}} \\
\hline & & & & & \\
\hline Great Worries & $31 \%$ & $22 \%$ & $34 \%$ & $22 \%$ & $37 \%$ \\
\hline Some Worries & $40 \%$ & $51 \%$ & $48 \%$ & $51 \%$ & $44 \%$ \\
\hline No Worries & $29 \%$ & $27 \%$ & $18 \%$ & $27 \%$ & $19 \%$ \\
\hline \multirow{2}{*}{\multicolumn{6}{|c|}{$\begin{array}{l}\text { Expect voluntary job } \\
\text { search in next } 2 \text { years }\end{array}$}} \\
\hline & & & & & \\
\hline Surely Not & $31 \%$ & $52 \%$ & $24 \%$ & $43 \%$ & $34 \%$ \\
\hline Rather Unlikely & $18 \%$ & $33 \%$ & $34 \%$ & $37 \%$ & $23 \%$ \\
\hline Likely & $24 \%$ & $10 \%$ & $24 \%$ & $14 \%$ & $21 \%$ \\
\hline Surely & $27 \%$ & $4 \%$ & $18 \%$ & $6 \%$ & $22 \%$ \\
\hline \multicolumn{6}{|c|}{ Expect to lose job } \\
\hline \multicolumn{6}{|c|}{ in next 2 years } \\
\hline Surely Not & $30 \%$ & $24 \%$ & $15 \%$ & $21 \%$ & $32 \%$ \\
\hline Rather Unlikely & $40 \%$ & $59 \%$ & $52 \%$ & $61 \%$ & $47 \%$ \\
\hline Likely & $20 \%$ & $12 \%$ & $19 \%$ & $13 \%$ & $11 \%$ \\
\hline Surely & $11 \%$ & $4 \%$ & $14 \%$ & $5 \%$ & $10 \%$ \\
\hline
\end{tabular}

Notes: The displayed sample sizes refer to the number of individuals in the data that the values are based on. Results with "No IPW" are weighted by population weights and the results for job changers and stayers "With IPW" are additionally reweighted to reflect the distribution of control variables among migrants using IPW. Results refer to the year before migration/job change for migrants and job changers. For stayers, each year between 1993 and 2003 is counted.

Source: Own calculations based on SOEP v30. 
Table 10: Attachment to Place of Living and Willingness to Move Years -4 to -2

\begin{tabular}{|c|c|c|c|}
\hline & \multicolumn{3}{|c|}{ Groups } \\
\hline & Migrants & Stayer & Job Changer \\
\hline \multicolumn{4}{|l|}{ Attachment to Place of Living } \\
\hline Very Strong & $30 \%$ & $31 \%$ & $26 \%$ \\
\hline Strong & $46 \%$ & $48 \%$ & $57 \%$ \\
\hline Weak & $21 \%$ & $19 \%$ & $14 \%$ \\
\hline None & $3 \%$ & $3 \%$ & $3 \%$ \\
\hline $\mathrm{N}$ & 149 & 16776 & 2102 \\
\hline \multicolumn{4}{|l|}{ Conceivable to move away } \\
\hline \multicolumn{4}{|l|}{ (job- or family-related) } \\
\hline Yes & $36 \%$ & $22 \%$ & $19 \%$ \\
\hline Depends & $46 \%$ & $42 \%$ & $41 \%$ \\
\hline No & $18 \%$ & $37 \%$ & $41 \%$ \\
\hline $\mathrm{N}$ & 198 & 24906 & 3087 \\
\hline \multicolumn{4}{|l|}{ Conceivable to move } \\
\hline \multicolumn{4}{|l|}{ to the West } \\
\hline Yes & $9 \%$ & $4 \%$ & $8 \%$ \\
\hline Under some circumstances & $68 \%$ & $64 \%$ & $59 \%$ \\
\hline Rather not & $14 \%$ & $25 \%$ & $28 \%$ \\
\hline Definitely not & $9 \%$ & $7 \%$ & $6 \%$ \\
\hline $\mathrm{N}$ & 139 & 9769 & 1287 \\
\hline \multicolumn{4}{|c|}{$\begin{array}{l}\text { Notes: The displayed sample sizes refer to the number of individuals in the data that the values are } \\
\text { based on. All results are weighted by population weights and the results for job changers and stayers are } \\
\text { reweighted to reflect the distribution of control variables among migrants. Results refer to the years } 2 \\
\text { to } 4 \text { years before migration/job change for migrants and job changers. For stayers, each year between } \\
1994 \text { and } 2004 \text { is counted can be the potential treatment year. So each stayer is replicated virtually } 10 \\
\text { times and for each of these stayers the results from } 2 \text { to } 4 \text { years before the hypothetical treatment time } \\
\text { are counted if available. } \\
\text { Source: Own calculations based on SOEP v30. }\end{array}$} \\
\hline
\end{tabular}


Table 11: Expectations and Worries, Years -4 to -2

\begin{tabular}{lccc}
\hline \hline & \multicolumn{3}{c}{ Groups } \\
& Migrants & Stayer & Job Changer \\
\hline \hline Optimism about & & & \\
the future & & & \\
Definitely & $9 \%$ & $10 \%$ & $9 \%$ \\
Rather Yes & $44 \%$ & $41 \%$ & $52 \%$ \\
Rather Not & $33 \%$ & $39 \%$ & $33 \%$ \\
Definitely Not & $14 \%$ & $10 \%$ & $6 \%$ \\
N & 100 & 10770 & 1341 \\
\hline Worries own economic & & & \\
situation & & & \\
Great Worries & $36 \%$ & $33 \%$ & $33 \%$ \\
Some Worries & $51 \%$ & $56 \%$ & $57 \%$ \\
No Worries & $14 \%$ & $11 \%$ & $10 \%$ \\
N & 279 & 37846 & 4161 \\
\hline Worries own job & & & \\
safety & & & \\
Great Worries & $16 \%$ & $13 \%$ & $15 \%$ \\
Some Worries & $53 \%$ & $60 \%$ & $60 \%$ \\
No Worries & $32 \%$ & $21 \%$ & $20 \%$ \\
N & $52 \%$ & $51 \%$ & $51 \%$ \\
\hline Expect voluntary job & $16 \%$ & $26 \%$ & $19 \%$ \\
Search in next 2 years & 161 & 28413 & 1875 \\
Surely Not & & & \\
Rather Unlikely & $26 \%$ & $37 \%$ & $35 \%$ \\
Likely & $35 \%$ & $36 \%$ & $37 \%$ \\
Surely & $21 \%$ & $20 \%$ & $17 \%$ \\
N & $18 \%$ & $7 \%$ & $12 \%$ \\
\hline Expect to lose job & & 12739 & 928 \\
\hline
\end{tabular}

Notes: The displayed sample sizes refer to the number of individuals in the data that the values are based on. All results are weighted by population weights and the results for job changers and stayers are reweighted to reflect the distribution of control variables among migrants. Results refer to the years 2 - 4 before migration/job change for migrants and job changers. For stayers, each year between 1994 and 2004 is counted can be the potential treatment year. So each stayer is replicated virtually 10 times and for each of these stayers the results from 2 to 4 years before the hypothetical treatment time are counted if available.

Source: Own calculations based on SOEP v30. 


\section{Figures}

\section{Figure 16: Earnings and Unemployment after IPW by treatment year}
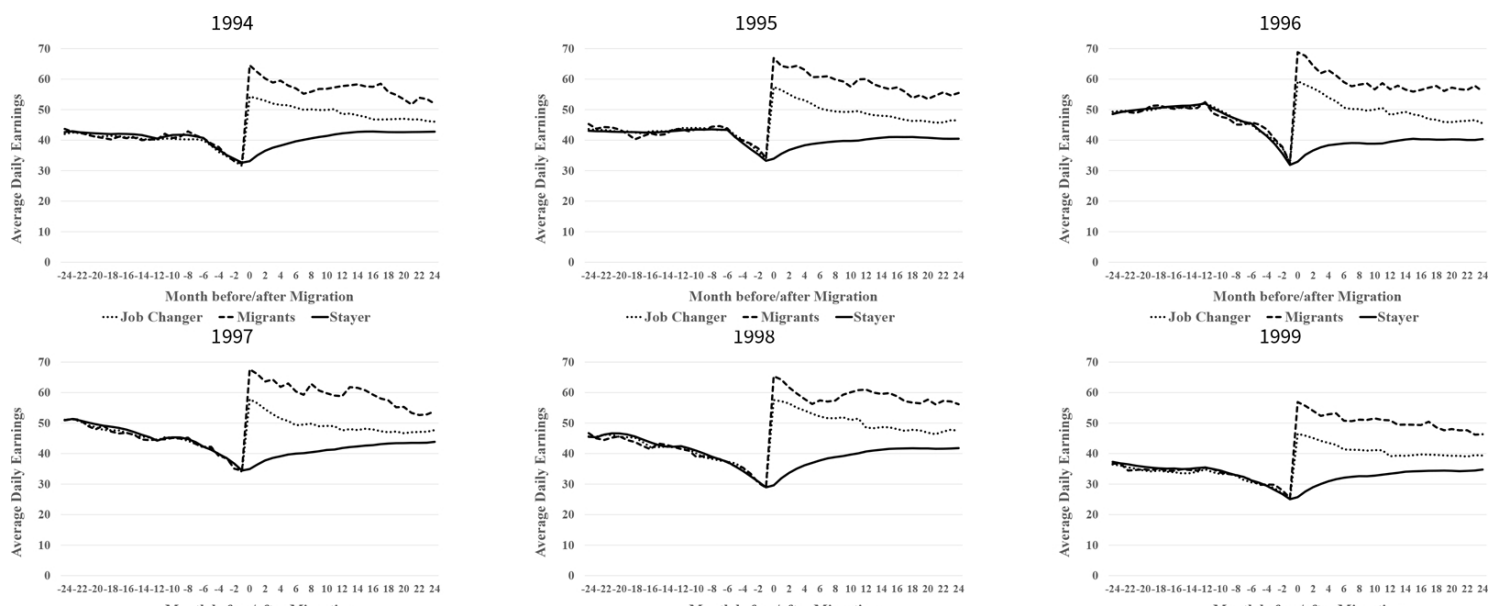

Month before/after Migration

Month beforelafter Migration
.... Job Changer - Migrants - Stayer

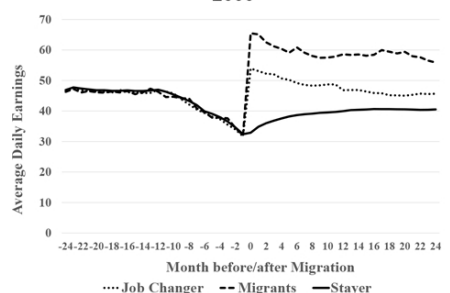

-....Job Changer --Mis

Ionth before/after Migration

....Job Changer -- Migrants - Stayer

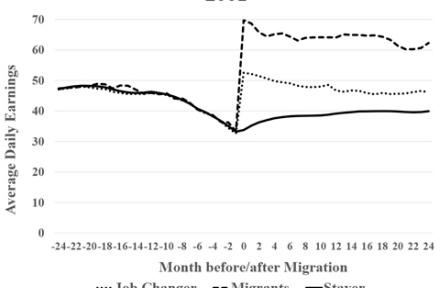

Month before/after Migration
Changer -- Migrants - Stayer

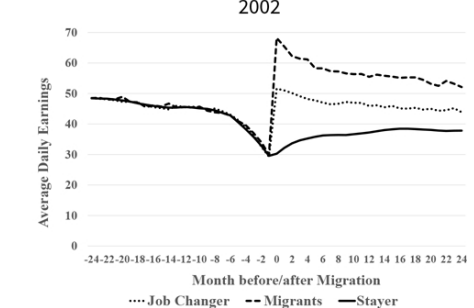

2003
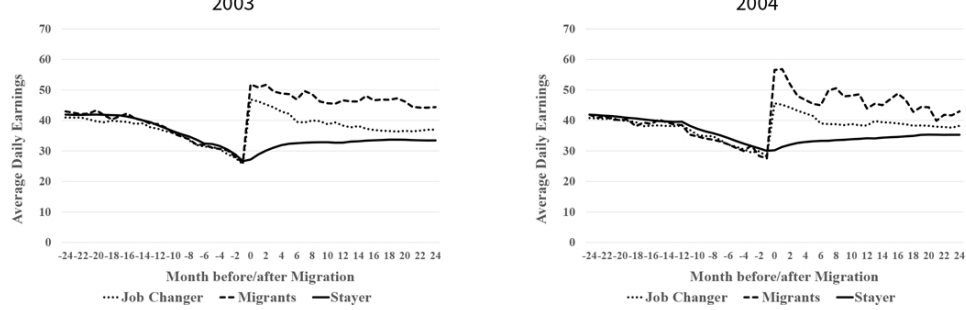

Notes: The figures show average daily earnings in relation to months before/after migration for the three treatment groups after IPW has been applied. The difference to the aggregate results in the text is that cohort-specific ATTs are not aggregated and reweighted based on the share of migrants in each cohort relative to all migrants, but that results for each cohort are displayed separately. As for the aggregate results, IPW are estimated separately for every migration cohort. Displayed years refer to the year of migration (the migration cohort) and results are displayed for the 24 month before and after the time of treatment. Source: Own calculations based on BASiD 5109. 


\section{Imprint}

\section{IAB-Discussion Paper 37|2020EN}

\section{Publication Date}

16 December 2020

Publisher

Institute for Employment Research

of the Federal Employment Agency

Regensburger Straße 104

90478 Nürnberg

Germany

All rights reserved

Reproduction and distribution in any form - also in parts - requires the permission of the IAB

Download

http://doku.iab.de/discussionpapers/2020/dp3720.pdf

All publications in the series "IAB-Discusssion Paper" can be downloaded from

https://www.iab.de/en/publikationen/discussionpaper.aspx

Website

www.iab.de/en

\section{Corresponding author}

Bernd Fitzenberger

E-Mail bernd.fitzenberger@iab.de 